\title{
1 Revisiting the depositional environment of the Neoproterozoic Callanna Group, South Australia
}

Eva E. Stüeken ${ }^{1,2, *}$, Roger Buick ${ }^{2,3}$, Timothy W. Lyons ${ }^{2,4}$

6 1. School of Earth \& Environmental Sciences, University of St Andrews, St Andrews, Fife, 7 KY16 9AL, Scotland, United Kingdom

8 2. Virtual Planetary Laboratory, University of Washington, Seattle, WA 98195, USA

9 3. Department of Earth \& Space Sciences, University of Washington, Seattle, WA 98195, USA

10 4. Department of Earth Sciences, University of California, Riverside, CA 92521, USA

$11 *$ corresponding author: ees4@st-andrews.ac.uk

13 Abstract

14 The Callanna Group was deposited around 800 million years ago (Ma) during an 15 interval in Earth's history that saw a transition towards a more oxygenated atmosphere, 16 increasing biodiversity among eukaryotic microfossils and climatic perturbations 17 culminating in low-latitude glaciations. Previous researchers proposed that the Callanna 18 basin was lacustrine and highly alkaline, which could provide important new insights into 19 environmental cause-effect relationships at this time. To further interrogate these records, 20 we examined standard biogeochemical proxies, including organic carbon and nitrogen 21 isotopes, iron speciation, metal abundances and carbonate-associated sulfate. Much of the 22 primary information has been lost because the rocks of the Callanna Group have experienced 23 extensive metamorphism up to amphibolite facies and are altered by modern weathering. 24 However, relics of these proxies, combined with sedimentological features, preserve 25 evidence of redox stratification within this basin. Furthermore, our observations, in 26 particular weakly fractionated nitrogen isotopes and abundant gypsum pseudomorphs, are 27 incompatible with the interpretation of high alkalinity. The high salt content and occurrences 28 of tidal indicators are most parsimoniously explained by frequent incursions of seawater. 29 Thus, the Callanna Group cannot speak straightforwardly to environmental conditions in 
non-marine habitats at this time. Lastly, the absence of a large carbon isotope anomaly indicates that these rocks do not correlate with the Bitter Springs Formation.

\section{Keywords}

Callanna Group; Neoproterozoic; evaporites; metamorphic alteration

\section{Introduction}

The early Neoproterozoic around $800 \mathrm{Ma}$ is an important transitional interval in the evolution of life and environments on the early Earth. It shows an increasing diversification of eukaryotic microfossils (Knoll and Nowak, 2017), reveals perhaps the first indications of local or intermittent oxygenation of the deep ocean (Thomson et al., 2015), and it records a major inflection in the chromium isotope record of marine sediments, which may indicate a second rise of atmospheric oxygen after the Great Oxidation Event in the Paleoproterozoic (Planavsky et al., 2014; Cole et al., 2016). Further, fundamental changes at this time may have set the stage for Sturtian glacial event that followed at roughly $720 \mathrm{Ma}$. However, the causeeffect relationships among these events continue to be debated and require new constraints from the rock record.

With the aim of filling some of the critical gaps in understanding, we turned to the Callanna Group in South Australia, which has been dated to around 800 Ma (Section 2.1, reviewed by Preiss, 2000). The Curdimurka Subgroup of the Callanna Group has previously been interpreted as representing a non-marine depositional environment, because it contains mineral pseudomorphs that were interpreted as shortite-a sodium-calcium carbonate mineral that is only found in alkaline lakes (Rowlands et al., 1980). Furthermore, fluvial sedimentation has been documented from other parts of the Callanna Group (Preiss, 1987). If these interpretations are correct, then the Callanna Group could provide rare insights into a non-marine habitat at this critical time in Earth's history. So far very little geochemical work has been done on these rocks, largely because of a strong metamorphic overprint and alteration by modern oxidative weathering. Although the interpretive power of common biogeochemical proxies is certainly limited under these conditions, we present

59 here new geochemical data, which in combination with sedimentological observations, 60 provide new constraints on the depositional setting of the Curdimurka Subgroup. Our study 
61 also highlights the possibility of extracting primary depositional information from rocks that

62 are highly altered.

\section{Geologic Setting}

\subsection{Tectonic setting and age constraints of the Callanna Group}

The Callanna Group is the basal stratigraphic unit in the Adelaide Geosyncline (Figure 1a), which is the historic name of a Neoproterozoic rift basin located in South Australia (Preiss, 2000). At the time of deposition, South Australia was located at low latitude (McWilliams and McElhinny, 1980) and part of the Rodinia Supercontinent (Moores, 1991). The basin probably formed during incipient continental breakup, perhaps as a failed rift that opened toward the south (Von der Borch, 1980). Crustal thinning as a consequence of NESW-directed rifting created accommodation space for thick sedimentary packages in a northwesterly trending fault-bounded corridor that became the Adelaide Geosyncline (Preiss, 2000).

The Callanna Group is subdivided into the Arkaroola and Curdimurka subgroups (Preiss, 1987). Both are composed of siliciclastic sediments, carbonates, evaporites and minor volcanic flows but probably represent distinct phases of rifting. The depositional age of the Arkaroola Subgroup, which crops out primarily in the Peak and Denison Ranges and in the Mt. Painter region of the northeastern Flinders Ranges, is constrained to $\sim 830 \mathrm{Ma}$, based on $\mathrm{U}-\mathrm{Pb}$ and $\mathrm{Sm}-\mathrm{Nd}$ dates obtained from intermediate volcanics and associated dolerite dykes (reviewed by Preiss, 2000). Precise dating of these rocks has been hindered by an amphibolite facies metamorphic overprint. The overlying Curdimurka Subroup, which is the focus of this study, contains a thin tuff unit (Rook Tuff) that is dated to $802 \pm 10 \mathrm{Ma}$ (Fanning et al., 1986). The major outcrop areas of the Curdimurka Subgroup-from north to south-occur in the Peake and Denison Ranges, the Willouran Ranges, the Worumba Anticline and the Spalding Inlier, which may each represent tectonic sub-basins that were perhaps structurally isolated (Preiss, 1987). Samples for this study were collected from the Willouran Ranges-the type locality of the Curdimurka Subroup-and from the Worumba Anticline. The two sections have been tentatively correlated, based on lithostratigraphic correspondences (Preiss, 1987). 
(a)

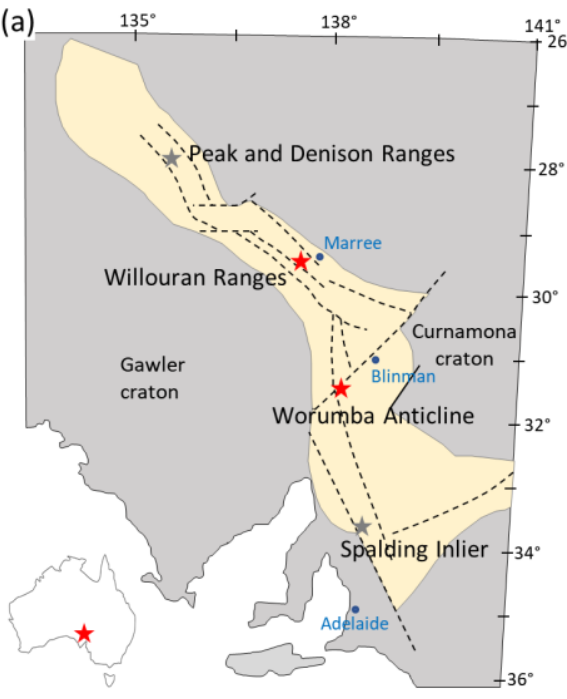

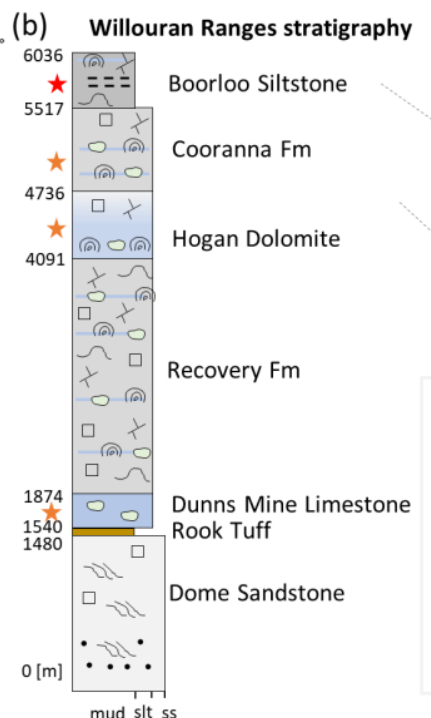

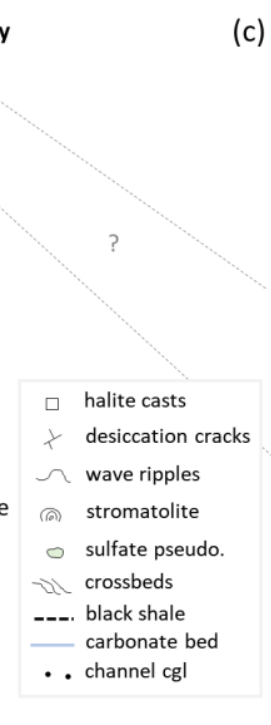

(c) Worumba Anticline stratigraphy

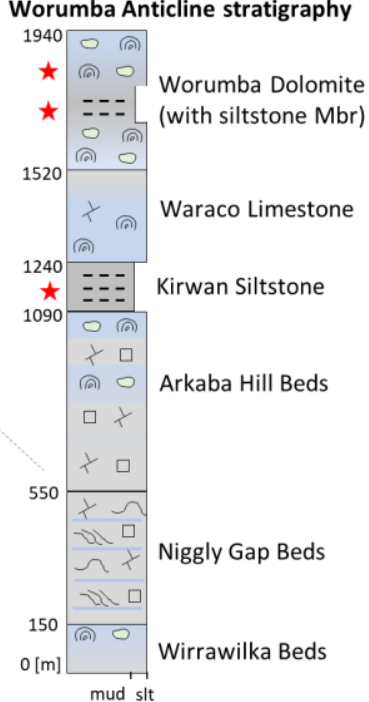

Figure 1: (a) Map showing the assumed extent of sedimentation of the Curdimurka Subgroup of the Callanna Group in the Adelaide Geosyncline (yellow shading), redrawn from Preiss et al. (1993). Red stars mark outcrop localities of the Curdimurka Subgroup sampled for this study. Grey stars are other outcrop localities that were not sampled for this project. (b) Schematic of the lithostratigraphy of the Curdimurka Subgroup in the Willouran Ranges, after Preiss (1987). Blue shaded units are dominated by carbonate (mostly dolomite), light and medium grey shaded units are dominated by siliciclastic siltstone and sandstone. Dark grey denotes mud. Grainsize indicators ( $x$-axis) denote mud, siltstone to fine sandstone (here sit) and medium to coarse sandstone (ss). Red stars mark major sampling localities; orange stars mark minor sampling sites. (c) Schematic of the lithostratigraphy of the Curdimurka Subgroup in the Worumba Anticline area. Symbols are as in panel $b$. We note that these stratigraphic columns are simplified and do not capture accurately the grainsize and position of specific features in the rock record.

\subsection{Stratigraphy of the Curdimurka Subgroup}

In the Willouran Ranges (Forbes et al., 1981; Preiss, 1987) the Curdimurka Subgroup is subdivided from oldest to youngest into the Dome Sandstone, the Rook Tuff (siltstone with porphyritic dacite lenses), the Dunns Mine Limestone, the Recovery Formation, the Hogan Dolomite, the Cooranna Formation and the Boorloo Siltstone (Figure 1b). In the Worumba Anticline, individual formations as described by Preiss (1987) include the Wirrawilka Beds, the Niggly Gap Beds, the Arkaba Hill Beds (possibly correlated with the Cooranna Fm in the Willouran Ranges), the Kirwan Silstone (possibly comparable to the Boorloo Siltstone in the Willouran Ranges), the Waraco Limestone and the Worumba Dolomite Beds (Figure 1c). Generally speaking, the Curdimurka Subgroup can be described as cyclically alternating 
118 siliciclastic and carbonate deposits, which may represent transgressive-regressive cycles 119 (Preiss, 1987).

120 Many of the siltstone units display desiccation cracks, teepees and halite casts; 121 nodular sulfate pseudomorphs occur in many of the carbonate beds throughout the 122 Curdimurka Subgroup. Based on these observations and facies associations, Preiss (1987) 123 interpreted the Curdimurka Subgroup as a coastal sabkha or playa lake environment that 124 became progressively more restricted from south to north. A non-marine interpretation of 125 the Willouran Ranges area was first proposed by Rowlands et al. (1980), who reported 126 pseudomorphs after shortite-a sodium-calcium carbonate mineral $\left(\mathrm{Na}_{2} \mathrm{Ca}_{2}\left(\mathrm{CO}_{3}\right)_{3}\right)$ that is 127 only found in alkaline lakes-from the Dunns Limestone and the Cooranna Formation in the 128 Willouran Ranges. The shortite pseudomorphs were observed to alternate with 129 pseudomorphs after gypsum.

According to this model, the Curdimurka Subgroup in the Willouran Ranges was 131 deposited in a lacustrine setting similar to the modern East African rift valley, where alkaline 132 saline lakes are common as a result of aqueous alteration of fresh volcanic rocks, followed 133 by evapo-concentration of ions (Garrels and Mackenzie, 1967; Kempe and Kazmierczak, 134 2011). The presence of analgous alkaline lakes has been suggested for the Neoproterozoic 135 Damara Belt in Namibia where similar mineralogical features were identified in a rift basin 136 of roughly the same age as the early Adelaide Geosyncline (Porada and Behr, 1998). Hill and 137 Walter (2000) argued in favour of the lacustrine model for the Curdimurka Subgroup in 138 South Australia, because they found unusually light carbon isotope ratios $\left(\delta^{13} C_{\text {carb }}\right.$ down to $1399.5 \%$ ) in some carbonates, which they interpreted as recording oxidation of terrestrial 140 biomass in the absence of a strong marine buffer of dissolved inorganic carbon (DIC). It 141 should be noted, however, that such a buffer should be even stronger in an alkaline lake 142 where DIC is more abundant than in seawater. Isotopically heavy carbonates up to $+2 \%$, 143 specifically in the Hogan Dolomite, were interpreted by Hill and Walter (2000) as reflecting 144 a marine incursion into the basin, but given the coarse sampling resolution of their study, 145 they were unable to identify regional consistencies.

146 To further investigate the environmental setting, we collected samples of carbonates 147 and carbonaceous siltstones from the Willouran Ranges and Worumba Anticline areas. New 148 sedimentological observations were paired with geochemical analyses. High-resolution 
sections were collected from the Boorloo Siltstone, the Kirwan Siltstone and the Worumba Dolomite. Due to post-depositional deformation, metamorphic overprinting and modern weathering, it was difficult to obtain unaltered material. This study is therefore in part an attempt to 'see through' intense alteration to extract new environmental information about this setting during a key interval in Earth's history.

\section{Materials and methods}

\subsection{Sampling}

We conducted traverses in the Willouran Ranges area from the basal Dome Sandstone to the top of the Boorloo Siltstone. Most samples for geochemical analyses were collected from the Boorloo Siltstone, including the type section (Section 1 from $29.7264^{\circ} \mathrm{S} / 137.9772^{\circ} \mathrm{E}$ to $29.7238^{\circ} \mathrm{S} / 137.9821^{\circ} \mathrm{E}$, locally known as Gum Creek) and three parallel sections separated by a few kilometers (section 2: $29.7187^{\circ} \mathrm{S} / 137.9650^{\circ} \mathrm{E}$ to $29.7210^{\circ} \mathrm{S} / 137.9661^{\circ} \mathrm{E}$; section $3: 29.7129^{\circ} \mathrm{S} / 137.9452^{\circ} \mathrm{E}$ to $29.713^{\circ} \mathrm{S} / 137.9451^{\circ} \mathrm{E}$; section 4: $29.7535^{\circ} \mathrm{S} / 137.9798^{\circ} \mathrm{E}$ to $29.7559^{\circ} \mathrm{S} / 137.9777^{\circ} \mathrm{E}$ ). The four sections were correlated using the prominent carbonate ridges at the top of the Boorloo Siltstone as marker beds. The Boorloo Siltstone is stratigraphically variable and can be broadly subdivided into seven intervals at the type locality (Figure 2):

I. 0-62 m: siltstone with sandstone interbeds of several $\mathrm{dm}$ in thickness. Wave ripples (symmetric, a few $\mathrm{cm}$ in scale here and elsewhere) and flaser bedding are common. Carbonate beds and calcareous sandstones at the scale of a few $\mathrm{dm}$ are present but rare.

II. 62-107 m: interlaminated siltstone and shale with wave ripples and frequent dolomitic carbonate interbeds of a few $\mathrm{dm}$ in thickness. Some carbonate beds display wavy lamination, defined by siliciclastic laminae, but most beds are massive and fine crystalline (sparry). Several horizons have a sooty appearance, possibly reflecting pyrobitumen after hydrocarbon migration (Figure $3 \mathrm{c}$ and discussion below)

III. 107 - 226 m: plane laminated siltstone with shale partings (Figure 3a). Sedimentary features indicative of current flow, wave action or exposure are absent.

IV. $226-270 \mathrm{~m}$ : plane laminated black shale with minor siltstone laminae (Figure 4h), lacking other sedimentary features. 
179

180

181

182

183

184

185

186

187

188

189
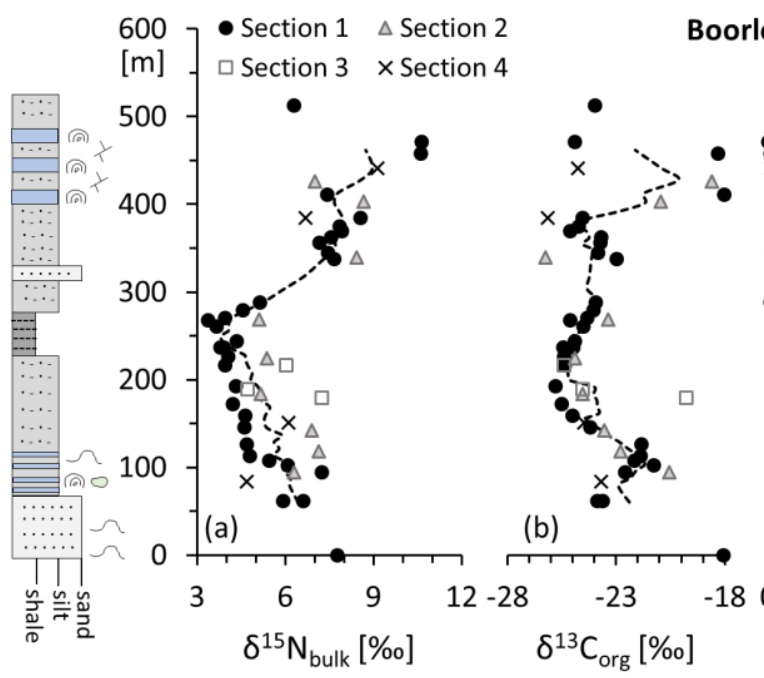
internal features. thickness. Frequent wave ripples. cracks indicating exposure (Figure $4 \mathrm{~g}$ ).

ing upwards into a massive sandstone bed (roughly 310-330 m), which probably represents a single sand sheet as it contains no

VI. 330 - $395 \mathrm{~m}$ : interlaminated siltstone and shale with minor sandstone interbeds of $\mathrm{dm}$

VII. 395 - $513 \mathrm{~m}$ : siltstone and shale with frequent thick (up to meter-scale) stromatolitic dolomite interbeds. The siltstone displays wave ripples and occasionally desiccation

190

Figure 2: Stratigraphic data along the Boorloo Siltstone in the Willouran Ranges. Symbols for

191 sedimentary features are as in Figure 1. Blue shading indicates carbonate. The four sections (1-

192 4) are a few kilometres separated from each other along strike and were correlated by the

193

prominent carbonate ridges at the top of the unit. The dashed line is the 5-point running mean. 

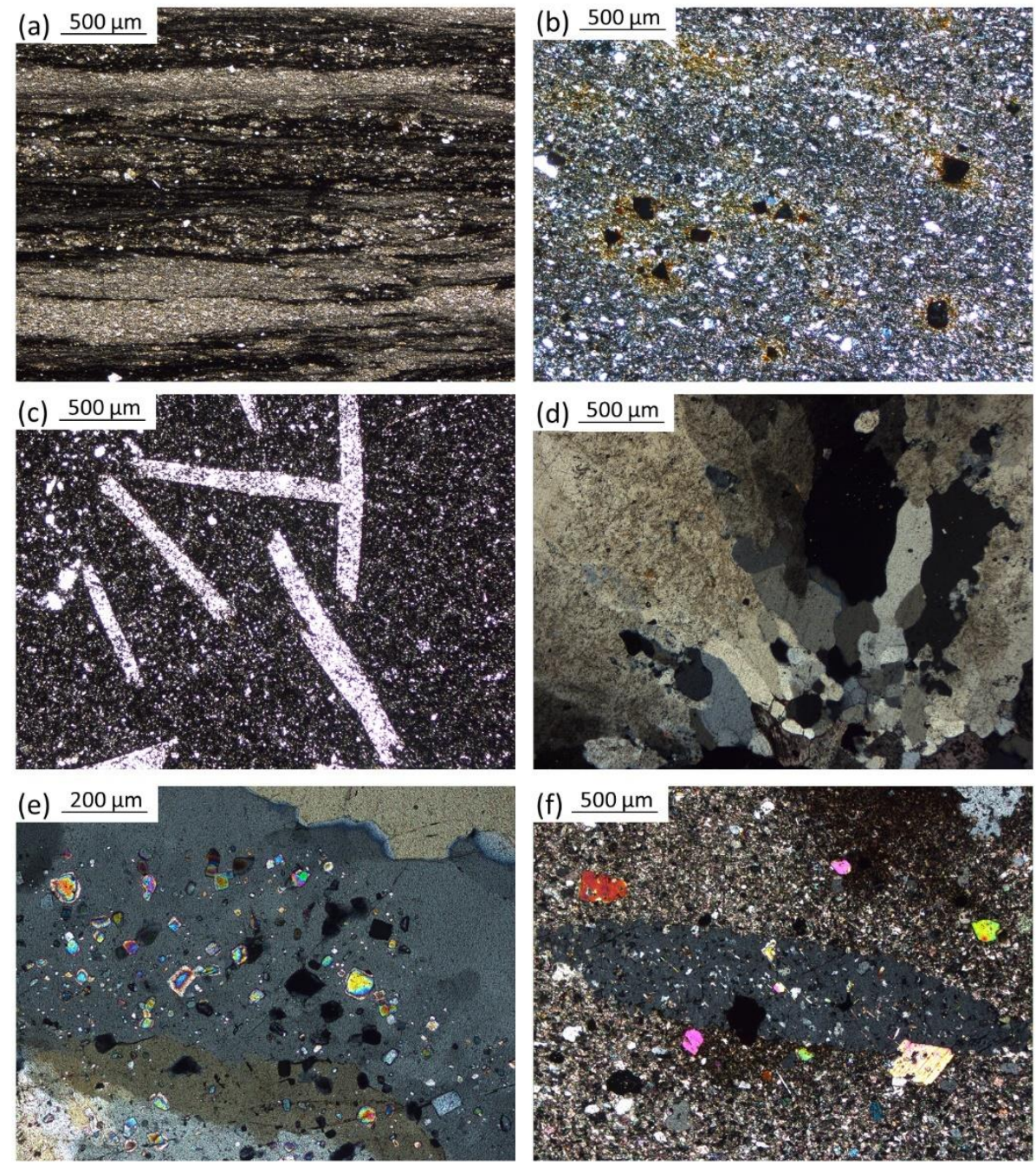

198 Figure 3: Photomicrographs of samples in the Willouran Ranges and Worumba Anticline area. 199 (a) Boorloo Stiltstone with shale laminae and minor carbonate; plane-polarized light. (b) Cubic 200 hematite grains, likely after diagenetic pyrite, in the Kirwan Siltstone; crossed polarizers. (c) 201 Monoclinic acicular quartz, likely pseudomorphs after diagenetic gypsum, within a matrix of 202 sooty pyrobitumen in the basal Boorloo Siltstone; plane-polarized light. (d) Rosette fabric in 203 quartz nodule within carbonate in the Hogan Dolomite; cross polarizers. (e) Inclusions with 204 second-order birefringence, likely anhydrite, within nodular quartz, likely after gypsum or 205 anhydrite, in the Worumba Dolomite; crossed polarizers. (f) Lenticular pseudomorph after 206 gypsum, now quartz, within the basal Boorloo Siltstone; crossed polarizers. 

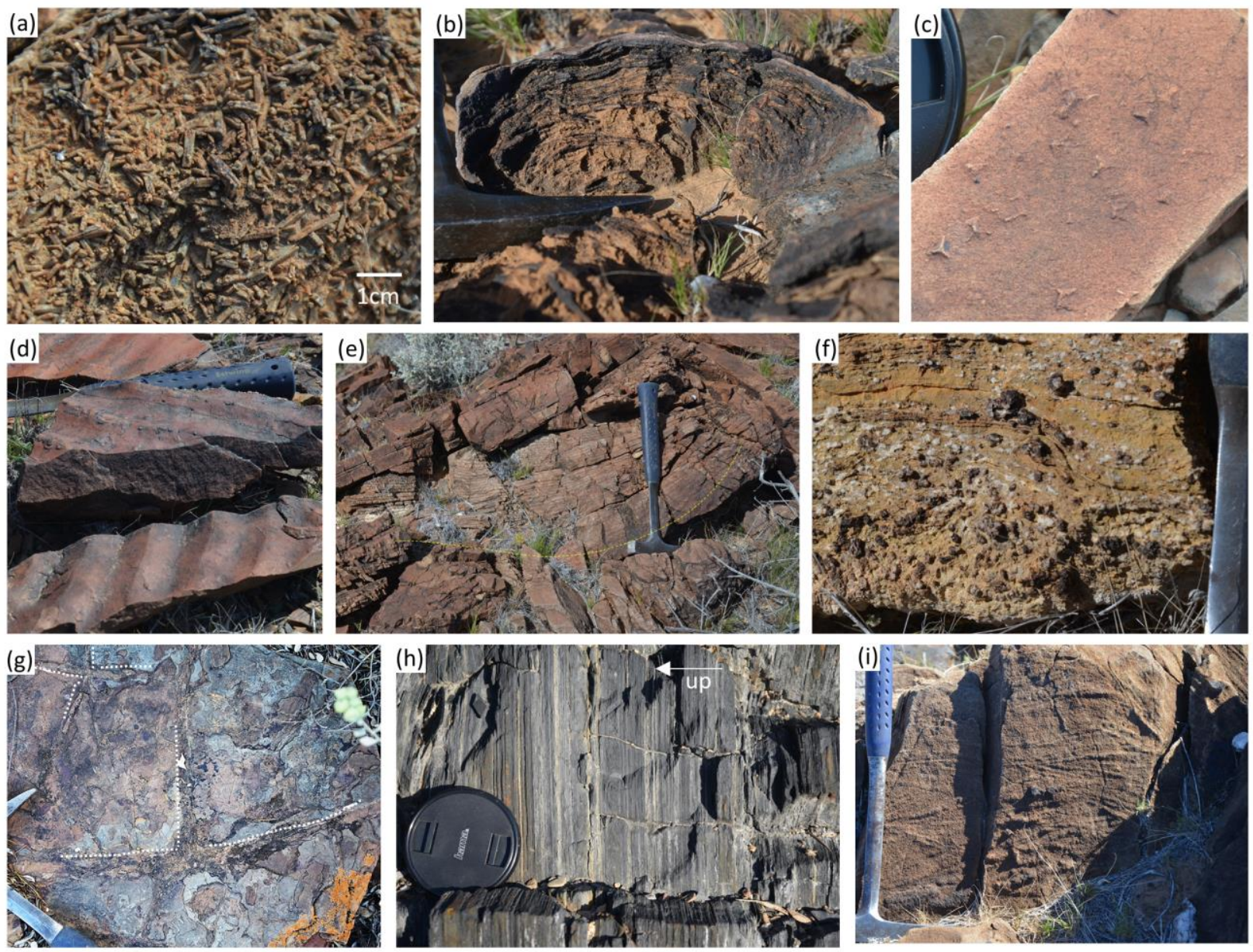

Figure 4: Field photos of the Curdimurka Subgroup in the Willouran Ranges area. (a) 'Matchstick' texture of putative pseudomorphs after shortite in the Cooranna Fm, alternatively identified as pseudomorphs after barite. (b) Domal stromtatolite from the Hogan Dolomite, a common morphology in several stratigraphic units. (c) Halite casts in siltstone from the Recovery Fm. (d) Wave ripples in siltstone slabs from the Recovery Fm. (e) Channel deposit (yellow dashed line) in the Dome Sandstone. Conglomeratic lag deposits are common at the bases of these channels. (f) Microbial carbonate with chert nodules after gypsum or anhydrite, reminiscent of chicken-wire fabric. (g) Desiccation cracks (white dotted lines) in the upper Boorloo Siltstone. (h) Plane laminated silty shale, partially calcareous, in the middle Boorloo

222 Thus, broadly speaking, the section shows fining toward the middle; carbonates and wave

223 ripples are restricted to the base and top. Oxidation trails, possibly after pyrite, are observed 224 in many of the mudrocks. The carbonates are iron oxide stained (Figure 4b and 4f). 225 Additional samples of carbonates and siltstones in the Willouran Ranges area were collected 
226 from the Dunns Limestone (around $29.7479^{\circ} \mathrm{S} / 137.9237^{\circ} \mathrm{E}$ ), the Hogan Dolomite (around $22729.7599^{\circ} \mathrm{S} / 137.9584^{\circ} \mathrm{E}$ ) and the Cooranna Formation (around $29.7548^{\circ} \mathrm{S} / 137.9719^{\circ} \mathrm{E}$ ). The 228 carbonates commonly contain nodular and lenticular gypsum or anhydrite pseudomorphs 229 (Figures 4f, 3f). A detailed stratigraphic description of these units is prohibited by the lack of 230 continuous exposure. Our samples were taken from continuous meter-thick beds that stand 231 proud above the more recessively-weathering calcareous mudstones above and below.
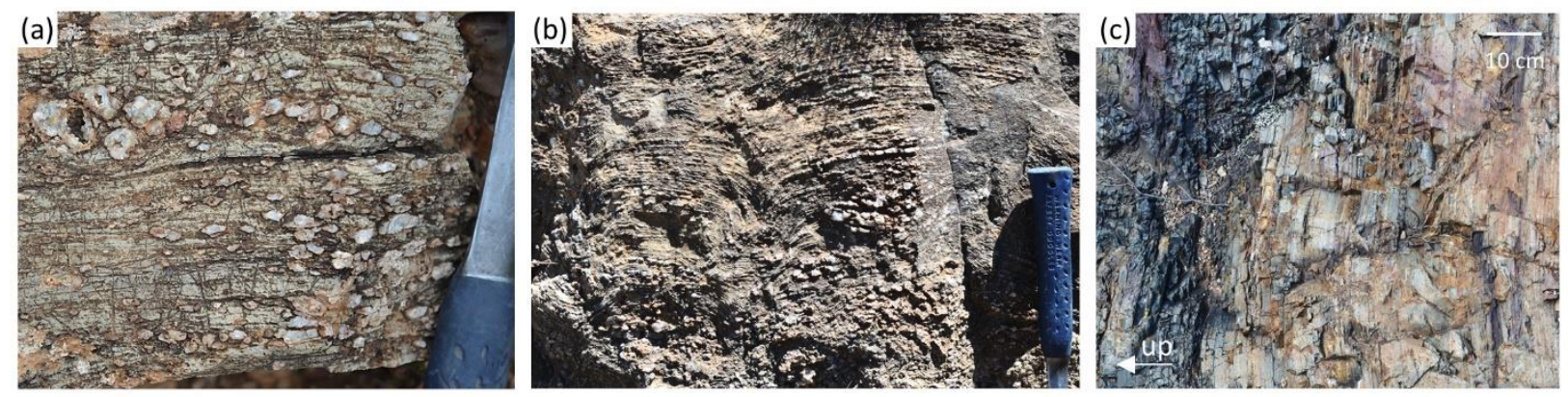

Figure 5: Field photos of the Curdimurka Subgroup in the Worumba Anticline area. (a) Nodular gypsum or anhydrite pseudomorphs in chicken-wire fabric within microbial carbonate of the Worumba Dolomite. (b) Stromatolitic carbonate with nodular gypsum or anhydrite pseudomorphs at the base in the Worumba Dolomite. (c) Plane-laminted Kirwin Siltstone.

In the Worumba Anticline, we targeted the most carbonaceous units, which are the Kirwan Siltstone $\left(31.9036^{\circ} \mathrm{S} / 138.6379^{\circ} \mathrm{E}\right.$ to $\left.31.9047^{\circ} \mathrm{S} / 138.6371^{\circ} \mathrm{E}\right)$ and the Worumba Shale Member $\left(31.8981^{\circ} \mathrm{S} / 138.6334^{\circ} \mathrm{E}\right.$ to $\left.31.8994^{\circ} \mathrm{S} / 138.6333^{\circ} \mathrm{E}\right)$. Both of these units are consist of plane-laminated silty shales, often with alternating silt and shale laminae (Figure

244 Oxidation trails with cubic pits (Figure 3b), likely after pyrite, were observed in some 245 samples, despite all efforts to sample below the modern weathering horizon. In addition to 246 the mudstones, we collected ten fairly evenly spaced samples from the Worumba Dolomite 247 over a stratigraphic interval of $3 \mathrm{~m}$ (around $31.8989^{\circ} \mathrm{S} / 138.6342^{\circ} \mathrm{E}$ ). The dolomite is wavy 248 laminated and often stromatolitic (Figure 5b). It displays chicken-wire fabric with nodular 249 gypsum or anhydrite pseudomorphs (now mostly quartz) of 1-2 cm in diameter (Figure 5a). 250 The nodules often display an internal rosette fabric (Figure 3d), and some anhydrite is 251 preserved (Figure 3e). The carbonate is stained with iron oxides. 


\subsection{Geochemical analyses}

We used standard geochemical techniques at the University of Washington, Seattle, and at the University of California, Riverside (e.g. Stüeken et al., 2017a). First, outer surfaces were removed with a water-cooled rock saw. The rocks were then broken into sub-cm sized chips and subsequently washed with methanol, $2 \mathrm{~N} \mathrm{HCl}$ and $\mathrm{DI}-\mathrm{H}_{2} \mathrm{O}(18 \mathrm{M} \Omega)$. The clean and dry chips were pulverized in a corundum puck mill, and the powder was stored in precombusted scintillation vials.

For bulk nitrogen and organic carbon analyses, a $\sim 0.5 \mathrm{~g}$ aliquot of powder was decarbonated with $6 \mathrm{~N} \mathrm{HCl}$ at $60^{\circ} \mathrm{C}$. The decarbonated powder was washed with DI-water, dried in a closed oven at $60^{\circ} \mathrm{C}$ and ultimately analysed by flash combustion in an elemental analyser (Costech) coupled to a gas source isotope ratio mass spectrometer (MAT253 Thermo Finnigan at UW). The isotopic ratios and elemental abundances were calibrated with in-house standards that had previously been calibrated to USGS-40 and USGS-41. Results are expressed in standard delta notation $\left(\delta=\left[\mathrm{R}_{\text {sample }} / \mathrm{R}_{\text {standard }}-1\right] \cdot 1000\right)$ relative to air for $\delta^{15} \mathrm{~N}$ and relative to VPDB for $\delta^{13} \mathrm{C}_{\text {org. }}$. Average reproducibility was $0.25 \%$ (1SD) for $\delta^{15} \mathrm{~N}$ and $0.07 \%$ for $\delta^{13} \mathrm{Corg}$.

Iron speciation was determined by sequential extraction of iron phases from carbonates ( $\mathrm{Fe}_{\mathrm{carb}}$, extracted with ammonium acetate), hematite ( $\mathrm{Fe}_{\mathrm{Hem}}$, extracted with sodium dithionate), magnetite ( $\mathrm{Fe}_{\mathrm{Mag}}$, extracted with ammonium oxalate), and pyrite (FePy, 272 extracted by chromium reduction) (Poulton and Canfield, 2005). For the first three phases, 273 the extracted iron was measured in solution with an inductively coupled plasma mass 274 spectrometer (Agilent 7500 at UCR). The calcium and magnesium concentrations of the ammonium acetate extract were used to approximate the total carbonate content of the samples (Stüeken et al., 2017a). The pyrite-bound iron was quantified by iodometric titration (Canfield et al., 1986). Highly reactive iron ( $\mathrm{Fe}_{\mathrm{HR}}$ ) is defined as the sum of $\mathrm{Fe}_{\mathrm{Hem}}$ $278 \mathrm{Fe}_{\mathrm{Mag}, \mathrm{Fe}}$ arb and Fepy (Poulton and Canfield, 2005). The average reproducibility of iron 279 measurements in replicate extractions was 13\%, but this uncertainty does not alter our 280 interpretation.

Carbonate-associated sulfate was extracted from carbonate samples following the 282 procedure described by Planavsky et al. (2012). Roughly 5-10 g of powder were treated 283 twice with a $10 \% \mathrm{NaCl}$ solution to remove any potential gypsum phases that may have 
284 formed during weathering of pyrite. The powder was then washed twice with DI-water and 285 treated several times with $10 \% \mathrm{H}_{2} \mathrm{O}_{2}$ overnight to remove pyrite as recommended by Wotte 286 et al. (2012). $\mathrm{H}_{2} \mathrm{O}_{2}$ treatments were stopped when no more $\mathrm{BaSO}_{4}$ precipitated in the 287 extracted solution upon addition of $\mathrm{BaCl}_{2}$. After another two DI-water rinses, the carbonate was mixed with $50-100 \mathrm{ml}$ of $4 \mathrm{~N} \mathrm{HCl}$ (excess to convert all carbonate to $\mathrm{CO}_{2}$ ) and left to react until no more bubbling could be observed. The solution was then separated from the residual

290 solids by filtration, and dissolved sulfate was precipitated as $\mathrm{BaSO}_{4}$ after the addition of $291 \mathrm{BaCl}_{2}$. The $\mathrm{BaSO}_{4}$ was separated by filtration and washed with approximately $50 \mathrm{ml}$ of $1 \mathrm{~N}$ $292 \mathrm{HCl}$, followed by $\sim 100 \mathrm{ml}$ of DI-water, and then dried overnight at $40^{\circ} \mathrm{C}$. A small aliquot of the $293 \mathrm{HCl}$ solution containing the dissolved carbonate was analysed for sulfate concentrations by 294 ICP-MS (Agilent 7500 at UCR). The $\mathrm{BaSO}_{4}$ was analysed for sulfur isotope ratios by EA-IRMS 295 (Costech EA, coupled to a Delta V Plus at UCR). A separate aliquot of each carbonate sample was subjected to chromium reduction to extract pyrite as $\mathrm{Ag}_{2} \mathrm{~S}$ for sulfur isotope analyses. The average reproducibility was $0.5 \%$ (1SD) for $\delta^{34}$, and values are expressed relative to 298 VCDT as a reference standard.

For bulk elemental analyses, a 1g aliquot of each sample was sent to ALS Global for analysis by ICP-MS and ICP-OES, following a four-acid digestion with $\mathrm{HNO}_{3}, \mathrm{HClO}_{4}, \mathrm{HF}$ and $\mathrm{HCl}$. Enrichment factors (EF) for redox-sensitive elements (X) relative to aluminium and bulk average crust were calculated as $\mathrm{EF}=\left(\mathrm{X}_{\text {sample }} / \mathrm{Al}_{\text {sample }}\right) /\left(\mathrm{X}_{\text {crust }} / \mathrm{Al}_{\text {crust }}\right)$, using crustal abundances from Rudnick and Gao (2014).

\section{Results}

\subsection{Iron speciation and redox-sensitive metals}

The samples were noticeably depleted in pyrite (Table 1), although the black shales in particular have been described as pyritic by previous authors (Rowlands et al., 1980; Preiss, 1987). Only two samples of the Boorloo Siltstone and one sample of the Worumba Shale Member contained pyrite above the detection limit of $0.1 \%$. In the siliciclastic 311 mudrocks, the ratio of highly reactive iron relative to total iron ( 312 the empirically defined oxic/anoxic threshold of 0.38 (Poulton and Canfield, 2011). Higher 313 ratios were predominantly found in samples with more than $30 \%$ carbonate, where $\mathrm{Fe}$ 314 ratios exceeded 0.7 (Figure 6a). Those samples also displayed total Fe/Al ratios greater than 
315 the continental average of 0.5 (Figure 6b), which is another empirically identified threshold

316 for anoxic conditions (Lyons et al., 2003; Lyons and Severmann, 2006; Raiswell et al., 2019).

317 It is important to note that the iron speciation proxy can also be applicable in carbonate-rich

318 rocks with more than $0.5 \% \mathrm{Fe}_{\mathrm{T}}$ (Clarkson et al., 2014), which is fulfilled for these samples.

319 The only sample that satisfies the iron criteria of euxinia (i.e., anoxic conditions with free $\mathrm{H}_{2} \mathrm{~S}$

320 in the water column) $-\mathrm{Fe}_{\text {нг }} / \mathrm{Fe}_{\mathrm{T}}>0.38$ paired with $\mathrm{Fe}$ ру $/ \mathrm{Fe}_{\mathrm{HR}}>0.7$ (Poulton and Canfield,

321 2011) - is the pyrite-bearing Worumba Shale sample (Figure 5c), which has a Fенк/Fет ratio

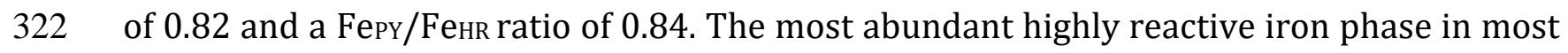

323 of the samples was hematite extracted with the Na dithionate treatment (Figure 6d).

324 Carbonate-bound iron was dominant in a few though not all carbonate-rich samples (Figure 325 5e). Magnetite constituted mostly less than 30\% (Figure 6f).
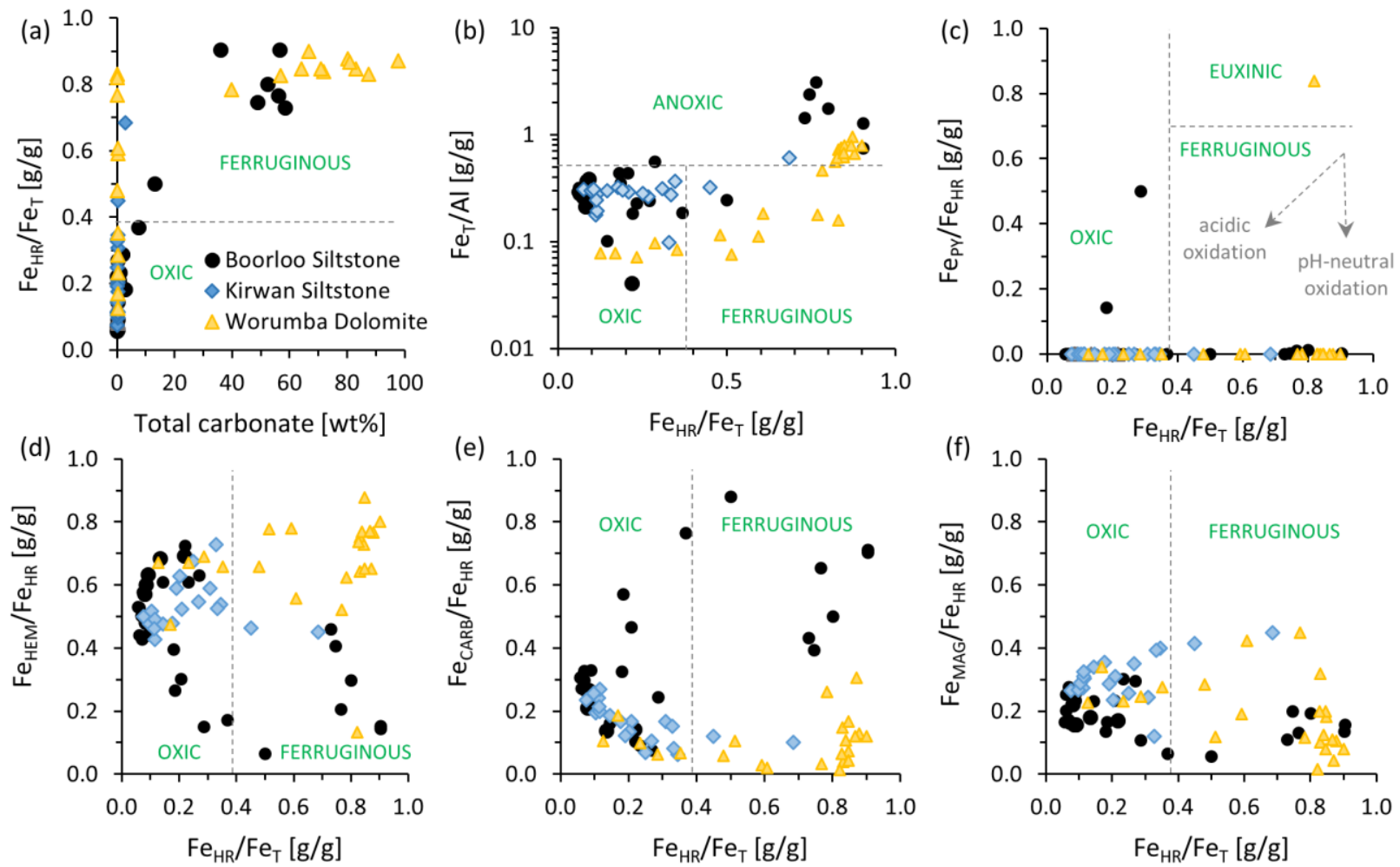

Figure 6: Iron speciation data. Dashed lines mark empirically defined thresholds of anoxia $\left(\mathrm{Fe}_{\mathrm{HR}} / \mathrm{Fe}_{\mathrm{T}}>0.38\right.$ and $\left.\mathrm{Fe} \mathrm{T}_{\mathrm{T}} \mathrm{Al}>0.5\right)$ and euxinia $\left(\mathrm{Fe}_{P y} / \mathrm{Fe}_{H R}>0.7\right)$ (Lyons et al., 2003; Poulton and Canfield, 2011). The high degree of modern oxidative weathering may have removed much if not all of the original pyrite, and sulfuric acid resulting from this process would likely have removed the $\mathrm{Fe}^{3+}$ from the host rock. Carbonates probably buffered this acidity, which could 334 explain relative iron retention compared to carbonate-poor mudstones. 
335 Concentrations of minor redox-sensitive metals (Table 2) were mostly close to crustal 336 background $(\mathrm{V}, \mathrm{Cr})$ or depleted by a factor of 3-5 ( $\mathrm{Co}, \mathrm{Ni}, \mathrm{Cu}, \mathrm{Zn}, \mathrm{As})$. Rare outliers with 337 enrichments above background levels are not systematic and show no covariance with pyrite 338 content or total organic carbon.

\subsection{Carbonate-associated sulfate and pyrite}

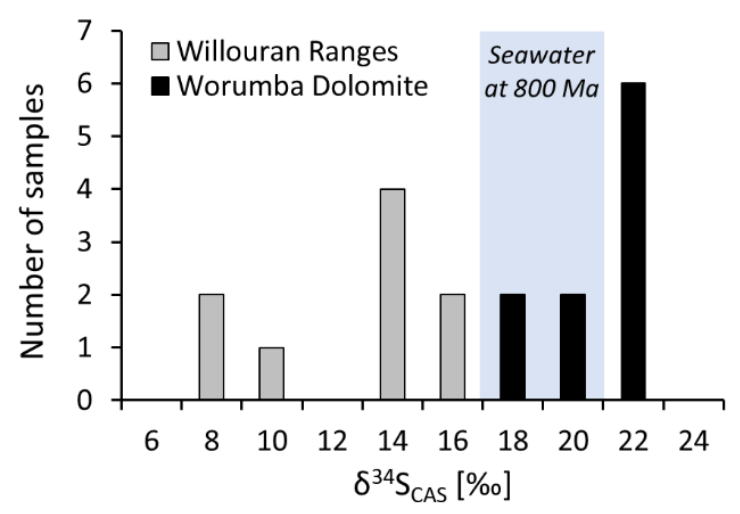

Figure 7: Carbonate-associated sulfate isotope data. Marine range is taken from Grojan et al. (2000) and Canfield \& Farquhar (2009).

348 from 273 ppm to 698 ppm (mean $439 \pm 130$ ppm) in the Worumba Dolomite and from $<1$

349 ppm to 142 ppm (mean $38+53 /-38$ ppm) in several scattered carbonates from the Willouran

350 Ranges area. We were able to measure sulfur isotope ratios for samples with at least $2.5 \mathrm{ppm}$

351 CAS and obtained $\delta^{34} S_{\text {CAS }}$ values of $+17.5 \%$ to $+20.9 \%$ (mean $+19.5 \pm 1.2 \%$ ) in the

352 Worumba Dolomite and $+7.2 \%$ to $+15.0 \%$ (mean $+11.4 \pm 2.8 \%$ ) in the Willouran samples

353 (Figure 7). Sulfur isotope data for trace amounts of pyrite $(<0.1 \%)$ contained in the same 354 samples showed a range of $-1.3 \%$ to $+6.5 \%$ (mean $+1.1 \pm 2.5 \%$ ) in the Worumba 355 Dolomite and $-14.6 \%$ to $+17.3 \%$ (mean $+1.1 \pm 9.2 \%$ ) in the Willouran samples. The 356 Worumba samples are thus overall more uniform in their CAS content and isotopic 357 composition. Minor amounts of pyrite (mostly <0.1\%) extracted from carbonate-poor shales 358 showed an isotopic composition of $+15.1 \%$ for the only pyrite-bearing sample from the 359 Worumba Shale Member and a range from $-8.6 \%$ to $+6.0 \%$ (mean $-1.5 \pm 8.0 \%$ ) in the 
Willouran shales from the Boorloo Siltstone (Table 3). A few other scattered samples from the Willouran area show values from $-12.4 \%$ to $+15.5 \%$ for extracted pyrite.

\subsection{Organic carbon and nitrogen isotopes and non-redox sensitive element ratios}

4.3.1. Boorloo Siltstone. For the Boorloo Siltstone, we collected samples along four parallel stratigraphic sections. The results agree well among the sections and will thus be discussed jointly. $\delta^{15} \mathrm{~N}$ values (Table 4) show a negative excursion in the middle of the unit, starting from around $+8 \%$ at the base, declining gradually to $+3 \%$ at round $250 \mathrm{~m}$, and recovering quickly to values between $+8 \%$ and $+11 \%$ (Figure 2 ). This trend is vaguely mirrored by an excursion in $\delta^{13} \mathrm{Corg}$, starting from values around $-21 \%$, declining to $-26 \%$, and returning to values around $-20 \%$ near the top. The relatively higher values in both parameters are thus found in the carbonate-rich beds and in particular in the stromatolitic intervals at the top, whereas the black shale in the middle of the section records the lowest isotopic ratios.

The total organic carbon (TOC) content reaches $2.6 \mathrm{wt} \%$ near the base but is mostly below $0.4 \mathrm{wt} \%$ for the rest of the section. The basal organic-rich samples have a sooty, reflective appearance, resembling metamorphosed concentrates of hydrocarbons. These exceptionally organic-rich beds are traceable along strike for a few meters (extent of the outcrop), have a thickness of 1-2dm and are more massive in appearance than adjacent beds (see also Figure 3c). We therefore interpret these data as indicative of hydrocarbon migration and concentration in between carbonate beds. In contrast to TOC, total nitrogen (TN) concentration shows a peak of $240 \mathrm{ppm}$ in the middle of the section, with lower values around $100 \mathrm{ppm}$ and $50 \mathrm{ppm}$ near the base and top, respectively.

As a consequence, there is only vague covariation between TN and TOC for a subset of samples. However, this lack of covariation is largely driven by the basal TOC-rich. Among all samples, the correlation coefficient $\left(\mathrm{r}^{2}\right)$ between TOC and TN is 0.07 (Figure $8 \mathrm{~b}$ ), but if samples above $1 \mathrm{wt} \%$ TOC and/or below $150 \mathrm{~m}$ are removed because of suspected pyrobitumen accumulation (Figure 3c), $\mathrm{r}^{2}$ increases to 0.52 (Figure 8c). Molar ratios of organic carbon to total nitrogen (hereafter $\mathrm{C} / \mathrm{N}$ ) mirror the trend in TOC, with high values near the base (Figure 2). TOC content and C/N ratios are strongly correlated $\left(\mathrm{r}^{2}=0.86\right.$, Figure 
391 8d), meaning that organic carbon is the main driver for large variations in $\mathrm{C} / \mathrm{N}$. If the basal 392 organic-rich samples are excluded, $\mathrm{r}^{2}$ drops to 0.47. Nitrogen isotopes are not correlated 393 with $\mathrm{C} / \mathrm{N}$ ratios $\left(\mathrm{r}^{2}=0.001\right.$, Figure $\left.8 \mathrm{a}\right)$, but they show a (non-linear) inverse covariance with $394 \mathrm{TN}\left(\mathrm{r}^{2}=0.74\right.$, Figure $\left.8 \mathrm{f}\right) . \delta^{15} \mathrm{~N}$ and TN are not correlated with $\mathrm{K} / \mathrm{Al}$ ratios $\left(\mathrm{r}^{2}=0.13\right.$ and 0.004 , 395 Figure 8e).

396

397
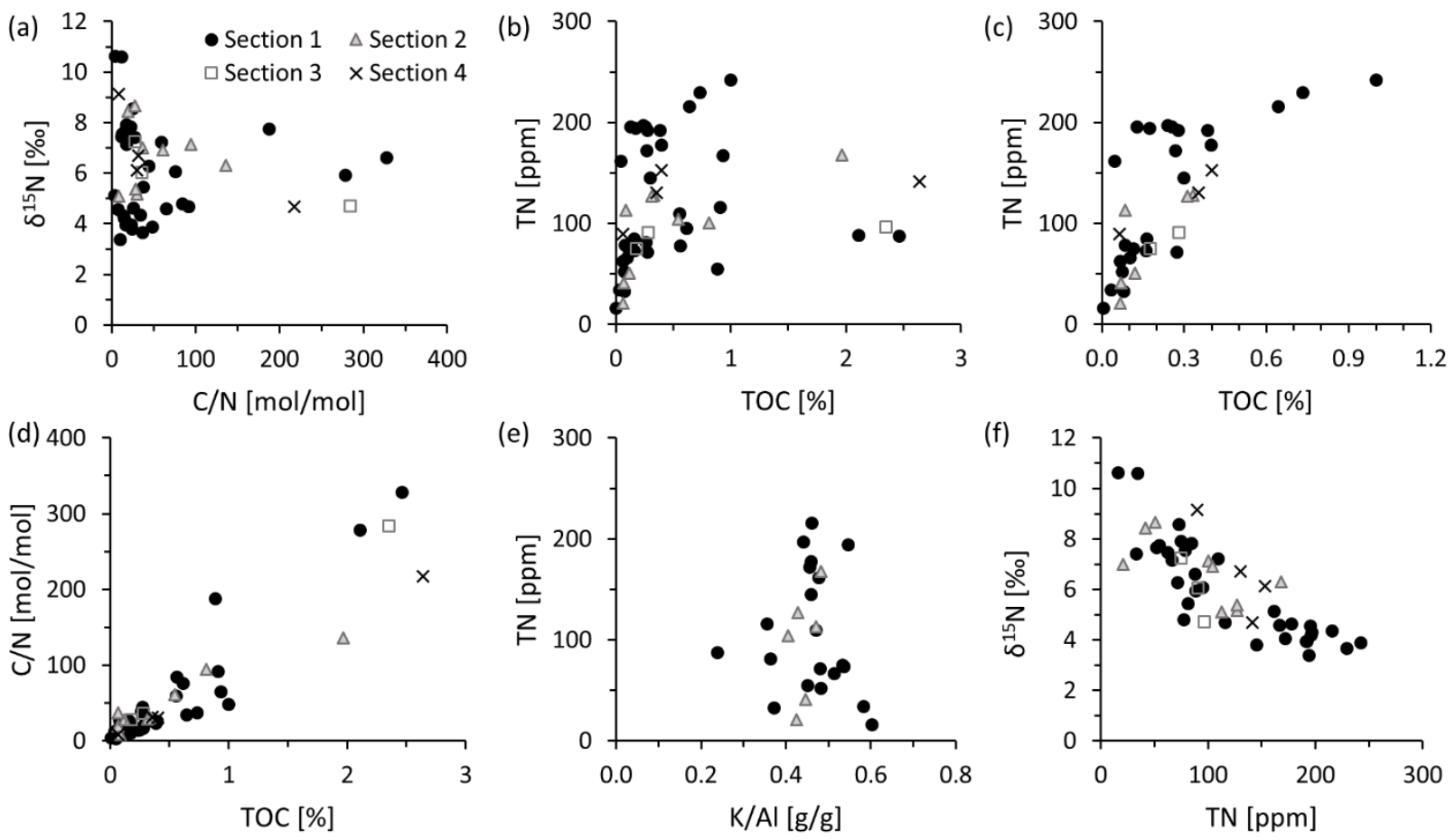

399 Figure 8: Scatter plots of nitrogen and related data in the Boorloo Siltstone. Panel c shows a 400 subset of the data from panel b, excluding samples with more than 1\% TOC and/or below 150 $401 \quad m$ where hydrocarbons may have migrated (Figure 3c).

402

403 

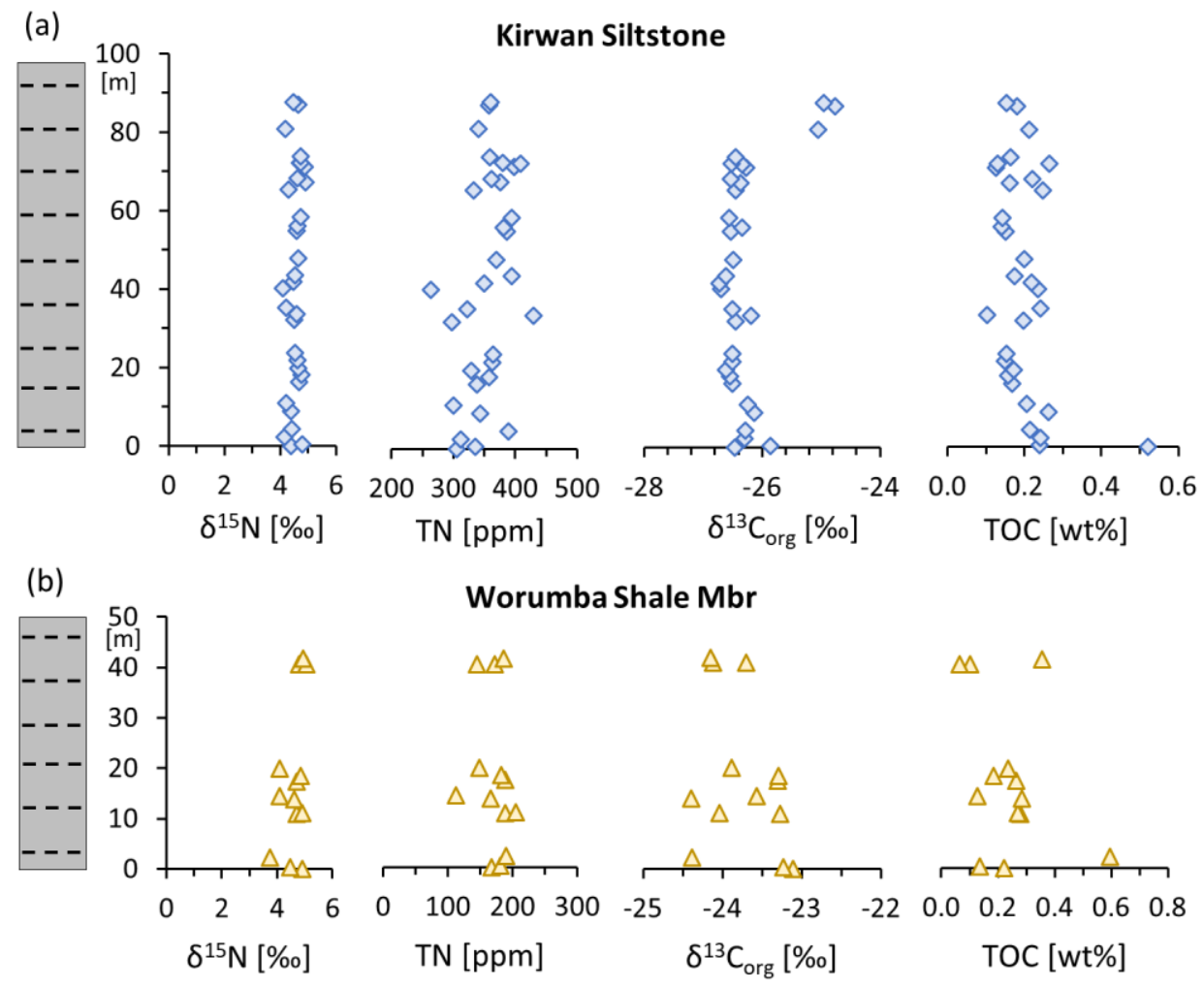

Figure 9: Stratigraphic data along the Kirwan Siltstone (a) and the Worumba Shale Mbr (b) in the Worumba Anticline region. Both units are relatively monotonous siltstones with interlaminated dark shale.

4.3.2. Kirwan Siltstone and Worumba Shale Mbr. Neither the Kirwan Siltstone nor the 410 Worumba Shale Member show any systematic stratigraphic variance in $\delta^{15} \mathrm{~N}, \mathrm{TN}, \delta^{13} \mathrm{C}_{\mathrm{org}}$, TOC 411 or $\mathrm{C} / \mathrm{N}$ (Figure 9). Nitrogen isotope data are similar between the two sections $(+4.5 \pm 0.2 \% 0$ 412 for the Kirwan Siltstone and $+4.6 \pm 0.4 \%$ for Worumba Shale Mbr), but the Kirwan Siltstone 413 is enriched in TN (355 $\pm 36 \mathrm{ppm})$ compared to the Worumba Shale Member (172 \pm 25 ppm). 414 TOC levels are $0.2 \pm 0.1 \mathrm{wt} \%$ on average in both sections, but $\delta^{13} \mathrm{C}_{\text {org }}$ is slightly heavier in the 415 Worumba Shale Mbr (-23.7 $\pm 0.5 \%$ ) compared to the Kirwan Siltstone $(-26.8 \pm 0.5 \%$ ). In 416 both sections, C/N ratios are strongly correlated with TOC $\left(\mathrm{r}^{2}=0.96\right.$ for the Kirwan Siltstone 417 and 0.95 for the Worumba Shale Mbr; Figure 10c). We did not find strong correlations 418 between nitrogen isotopes and $\mathrm{C} / \mathrm{N}$ ratios $\left(\mathrm{r}^{2}<0.4\right.$ for both sections, Figure 10a) or TN 419 contents $\left(r^{2}<0.4\right.$ in both cases, Figure $\left.10 \mathrm{~d}\right)$, nor between TN and TOC (both $\mathrm{r}^{2}<0.31$, Figure 420 10b). Also nitrogen abundances and isotope data are not correlated with $\mathrm{K} / \mathrm{Al}$ ratios $\left(\mathrm{r}^{2}<0.3\right.$ 421 and $<0.03$, respectively, for both sections, not shown). 

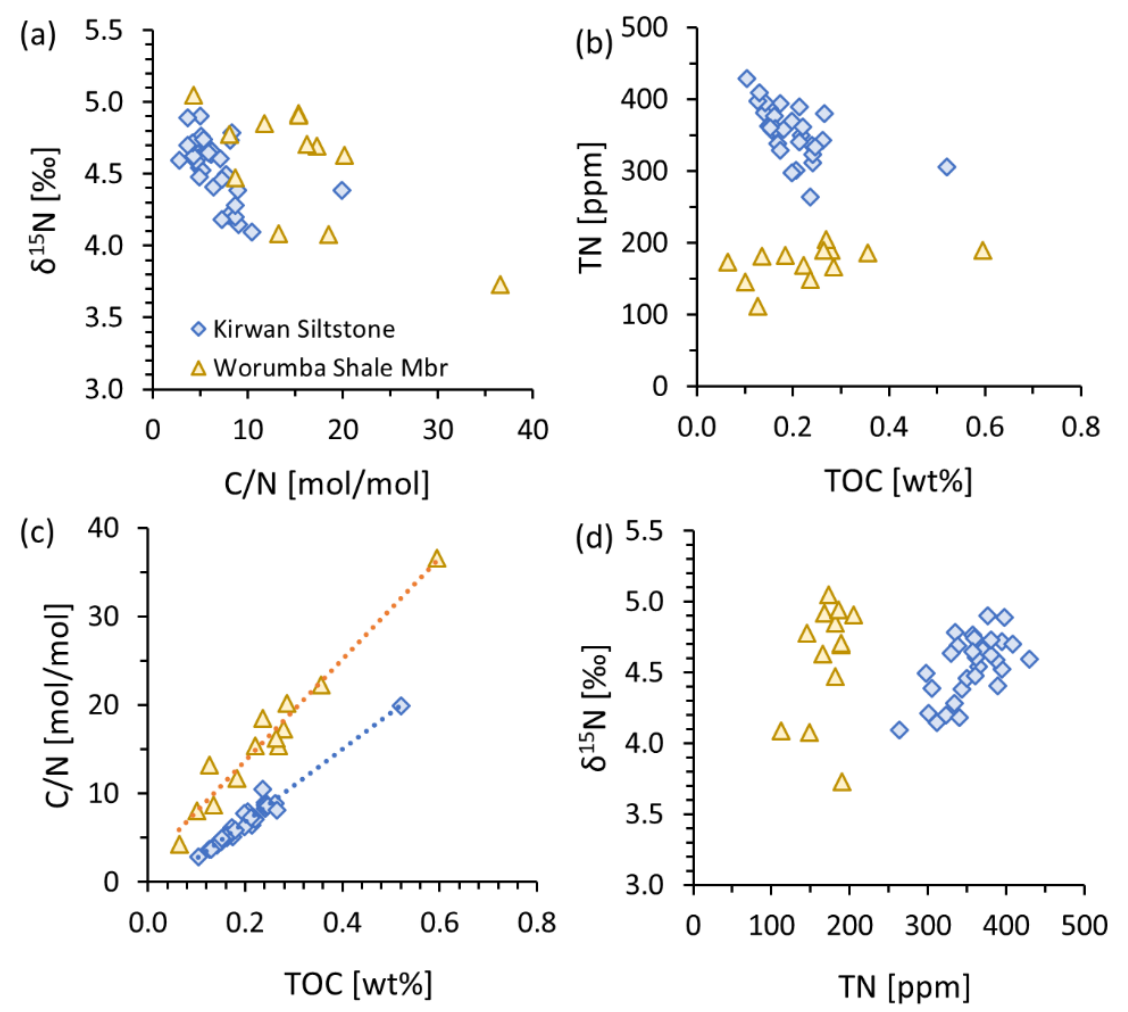

426 Figure 10: Scatter plots of nitrogen data for the Kirwan Siltstone (blue diamonds) and the 427 Worumba Shale Mbr (yellow triangles).

\section{Discussion}

\section{$430 \quad$ 5.1. Alteration by modern weathering}

431 5.1.1. Iron speciation and redox-sensitive elements. We suspect that the scarcity of pyrite may 432 largely be a consequence of modern oxidative weathering. Despite our efforts to dig deep 433 into the outcrops, many samples displayed small oxidation trails, sometimes in cubic shapes, 434 reminiscent of euhedral pyrite grains that may have formed during diagenesis with likely 435 metamorphic overprints (Figure 3b). Oxidative loss of sulphide phases could also explain the 436 depletion or lack of enrichment in redox-sensitive elements (V, Co, Ni, Cu, Zn, As). Oxidation of pyrite-bound $\mathrm{Fe}^{2+}$ to $\mathrm{Fe}^{3+}$ would perturb the iron speciation proxy. If the $438 \mathrm{Fe}^{3+}$ is retained within the rock as iron oxides, the Fepy/FenR ratio would drop, but the $439 \mathrm{Fe}_{\mathrm{HR}} / \mathrm{Fe}_{\mathrm{T}}$ ratio would stay constant. In this case, a sample that fell initially into the euxinic 
category (Fеру $/ \mathrm{Fe}_{\mathrm{HR}}>0.7$ and $\mathrm{Fe}_{\mathrm{HR}} / \mathrm{Fe}_{\mathrm{T}}>0.38$, Poulton and Canfield, 2011) would appear

441 ferruginous. If, however, some $\mathrm{Fe}^{3+}$ is lost during oxidation, $\mathrm{Fe}_{\mathrm{HR}} / \mathrm{Fe}_{\mathrm{T}}$ would drop together

442 with Fеру/Fенг, and the sample would move towards the 'oxic' field in a Fенг/Fет versus

$443 \mathrm{Fe}_{\mathrm{Py}} / \mathrm{Fe}_{\mathrm{HR}}$ crossplot. In our samples, it is noteworthy that the $\mathrm{Fe}_{\mathrm{HR}} / \mathrm{Fe}_{\mathrm{T}}$ ratio increases with

444 carbonate content (Figure 6a), whereas the siliclastic shales have lower ratios of Feнг/Fет. It

445 is likely that pyrite oxidation in shales generated sulfuric acid, which mobilised $\mathrm{Fe}^{3+}$ and

446 removed it from the system. In contrast, carbonate-rich samples may have buffered the

447 acidity, leading to $\mathrm{Fe}^{3+}$ retention as iron oxides. This interpretation is consistent with the

448 high ratios of diothionite-extracted iron to highly-reactive iron, where the former is assumed

449 to represent mostly hematite-bound $\mathrm{Fe}^{3+}$ (i.e., Feнем/Feнг) (Figure 6d). The implications are

450 that we are unable to infer redox conditions from iron speciation in the shale samples;

451 however, the carbonates appear to record anoxic conditions at the time of deposition (Figure

452 6a). We cannot speak to the presence or absence of euxinia with this proxy due to the

453 potential loss of pyrite, but the presence of gypsum/anhydrite nodular pseudomorphs with

454 chicken-wire fabric and the lack of highly negative $\delta^{34} \mathrm{~S}$ values in pyrite suggest that sulfate

455 was not totally consumed by microbial reduction in the water column, at least within the 456 carbonate facies.

457 Carbonate-associated sulfate can also be affected by weathering. Gill et al. (2008) 458 documented a significant drop in CAS concentrations during meteoric alteration of 459 Pleistocene carbonates. However, the isotopic record appeared to have been buffered and 460 was essentially unaltered. Oxidation of pyrite could potentially have created 'modern' sulfate 461 phases during weathering; however, since we cleaned our samples thoroughly with $\mathrm{NaCl}$ 462 solution and $\mathrm{H}_{2} \mathrm{O}_{2}$ (Wotte et al., 2012), any such modern sulfate, along with residual pyrite, 463 should have been removed from the rock prior to CAS extraction in the laboratory.

5.1.2. Organic carbon and nitrogen. Petch et al. $(2000 ; 2005)$ showed that organic carbon is oxidized more slowly than pyrite during oxidative weathering, which is consistent with our observation that at least some organic carbon was still present in these rocks despite the loss of pyrite. However, TOC levels have likely been reduced, and organic carbon isotope ratios may have become heavier by 1-2 \%o due to partial loss during weathering (Leythaeuser, 1973; Clayton and Swetland, 1978). 
Oxidative weathering has also been shown to lower the nitrogen contents of rocks

472 (Petsch et al., 2005), but the effects on nitrogen isotopes have to our knowledge not yet been

473 tested. A previous study (Stüeken et al., 2017b) showed that the majority of the total nitrogen

474 is contained in silicate minerals (Boorloo Siltstone 56-97\%, n=3; Kirwan Siltstone 96\%, $475 \mathrm{n}=3$; Worumba Shale Mbr 90-91\%, n=2). Nitrogen can partition into silicate minerals as 476 ammonium ions during diagenesis and metamorphism. Ammonium $\left(\mathrm{NH}_{4}^{+}\right)$has the same 477 charge as $\mathrm{K}^{+}$and a similar ionic radius, which allows it to substitute into K-rich minerals 478 (Müller, 1977; Schroeder and McLain, 1998). We speculate that this silicate-bound 479 ammonium fraction is relatively more resilient to oxidative weathering than organic-bound 480 nitrogen, which could in part explain the high relative abundance of silicate-bound nitrogen 481 in these rocks.

\subsection{Diagenesis and metamorphism}

Using $\mathrm{H} / \mathrm{C}$ ratios of kerogen isotopes, it has been shown that the Boorloo Siltstone experienced lower amphibolite facies metamorphism ( $\mathrm{H} / \mathrm{C}=0.06-0.09)$, whereas the Kirwan Siltsone and Worumba Shale Mbr $(\mathrm{H} / \mathrm{C}=0.13-0.22)$ have only been metamorphosed to greenschist facies (Stüeken et al., 2017b). Metamorphism can have significant effects on organic carbon and nitrogen isotopes. In both isotopic systems, the lighter isotope is volatilized more readily during metamorphic heating (e.g. Haendel et al., 1986; Bebout and 490 Fogel, 1992; Boyd and Phillippot, 1998; Palya et al., 2011). $\delta^{15} \mathrm{~N}$ and $\delta^{13} \mathrm{C}_{\text {org }}$ values thus tend 491 to increase with metamorphic grade. For nitrogen, the effect is on the order of $1-2 \%$ for 492 greenschist facies and 3-4\%o for amphibolite facies (reviewed by Thomazo and Papineau, 493 2013). Organic carbon isotopes increase by several permil during metamorphism, and this 494 effect is enhanced in the presence of carbonates (Schidlowski, 1987). It is therefore likely 495 that all our samples have been shifted to heavier isotopic values during regional metamorphism, and the effect was probably more significant in the Boorloo Siltstone than in

497 the Kirwin Siltstone and Worumba Shale Mbr, because the former is of higher metamorphic 498 grade (Stüeken et al., 2017b).

5.2.1. Nitrogen and carbon in the Boorloo Siltstone. The stratigraphic trends in the organic carbon isotope data may be an artefact of metamorphism, because the heavier values occur 
502 in the more carbonate rich interval above $400 \mathrm{~m}$ (Figure 2), as would be expected with 503 metamorphic isotopic equilibration between inorganic and organic carbon phases. However, 504 although it is likely that our nitrogen data have also been pushed to heavier values, 505 metamorphic volatilization probably cannot explain the stratigraphic variation in $\delta^{15} \mathrm{~N}$ across the Boorloo Siltstone as regional metamorphism should have affected the section as a whole. As noted above, $\delta^{15} \mathrm{~N}$ shows no covariance with $\mathrm{C} / \mathrm{N}$ ratios, even though $\mathrm{N}$ tends to 508 be lost more rapidly during metamorphism (Hayes et al., 1983). Nitrogen isotopes are instead correlated with TN contents (Figure 8f), where the highest TN contents occur in the black shale facies at around $250 \mathrm{~m}$, which also shows a small peak in TOC. Thus, this correlation seems to be a primary feature. The shale facies likely started out more organic512 rich and may have displayed lighter nitrogen isotope ratios as a consequence of redox 513 stratification (further discussed in Section 5.3.2).

We can rule out significant post-depositional migration of ammonium across the section, as well as major input of detrital ammonium, because TN contents correlates with 516 TOC but not with K/Al (Figures 8c, 8e). We note that the correlation between TN and TOC is 517 only observed after excluding some samples from the basal Boorloo Siltstone $(<150 \mathrm{~m})$ that 518 show evidence of hydrocarbon migration in the form of abnormally high $\mathrm{C} / \mathrm{N}$ ratios (Figure 519 2) and sooty organic carbon that is reminiscent of pyrobitumen (Figure 3c). Thus, while the 520 basal part of the section may yield unreliable isotopic values, the transition from light $\delta^{15} \mathrm{~N}$ 521 values in the middle black shale $(\sim 250 \mathrm{~m})$ toward heavier values in the stromatolitic facies 522 at the top ( $>400 \mathrm{~m}$, Figure 2 ) may be a primary relic of environmental conditions during the 523 time of deposition (Section 5.3.2). 5.2.2. Nitrogen and carbon in the Kirwan Siltstone and Worumba Shale Mbr. Unlike the 526 Boorloo Siltstone, the Kirwan Siltstone and the Worumba Shale Mbr are strikingly homogeneous in their TN content and isotopic composition. Another difference noted in a 528 previous study (Stüeken et al., 2017b) is that the $\delta^{15} \mathrm{~N}$ value of the kerogen in the Kirwan 529 Siltstone and Woruma Shale Mbr is further offset (by $3.9 \pm 0.0 \%$ and $4.5 \pm 0.4 \%$, respectively) from the $\delta^{15} \mathrm{~N}$ of the silicate-bound ammonium compared to the offsets in the

531 Boorloo Sitlstone $\left(3.0 \pm 0.1 \%\right.$ ). Divergence in $\delta^{15} \mathrm{~N}$ between the two nitrogen phases is 532 commonly observed with increasing regional metamorphic grade (Stüeken et al., 2017b) as 
533 well as after metasomatic fluid alteration (Godfrey et al., 2013). In this case, the Boorloo

534 Siltstone has a higher metamorphic grade (lower amphibolite facies) than the shales of the 535 Worumba Anticline (greenschist facies). Hence, the relatively large nitrogen isotope offset 536 between kerogen and silicates in the Kirwan Siltstone and Worumba Shale Mbr is perhaps not a metamorphic feature alone but may be evidence of metasomatic alteration. Such fluids could conceivably have homogenized the nitrogen contents and isotopic ratios within the two units.

As noted earlier (Section 5.1.2), ammonium released from the breakdown of organic matter during diagenesis partitions into K-rich minerals due to the similarity in ionic charge and size (Schroeder and McLain, 1998). For this reason it has been suggested that postdepositional ammonium migration may be linked to K-metasomatism, supported by correlations between TN and K contents in other datasets (Kump et al., 2011). We did not observe any such correlations in our samples (Section 4.3), which may indicate that ammonium and potassium migration were unrelated in this setting. Metasomatism with Krich fluids is often explained by the breakdown of K-rich feldspars and clay minerals (reviewed by van de Kamp, 2016). In contrast, ammonium is primarily sourced from biomass during either diagenetic decay or metamorphic breakdown. Hence, ammonium migration could have occurred independently from K-metasomatism, and a correlation between the two elements is perhaps not necessarily to be expected.

The most likely ammonium source rocks in the Worumba Anticline are the shales sampled for this study, as they are the most organic rich units in this area. Hence, ammonium was probably released from the most organic-rich laminae and distributed relatively evenly across organic-poor beds via incorporation into clays. If so, no nitrogen would have been added from external sources, and hence the average isotopic composition of the shales may still approximate the primary isotopic composition with only a slight metamorphic overprint

560 5.2.3. Alteration of inorganic proxies. Metamorphism has been shown to have significant 561 effects on iron speciation, where carbonate-bound iron can be transferred into silicates, 562 making the rock appear, if anything, relatively more 'oxic' (Slotznick et al., 2018). The anoxic 
563 (ferruginous or euxinic) conditions inferred from our carbonate samples are thus a 564 reasonable interpretation.

565 Carbonate-associated sulfate can be strongly modified during diagenesis where in 566 situ pyrite oxidation can lead to lower $\delta^{34}$ S CAS values (Marenco et al., 2008), while diagenetic 567 sulfate reduction can deplete porewater sulfate in ${ }^{32} \mathrm{~S}$, pushing $\delta^{34} \mathrm{~S}_{\mathrm{CAS}}$ higher (Fike et al., 568 2015). We cannot rule out either of these effects. However, the presence of 569 gypsum/anhydrite nodular pseudomorphs within the same carbonates in both outcrop 570 areas (Figures $4 \mathrm{f}, 3 \mathrm{~d}, 3 \mathrm{e}, 3 \mathrm{f}, 5 \mathrm{a}$ ); the relatively small scatter in $\delta^{34}$ ScAs, in particular in the 571 Worumba Dolomite and the moderately high CAS concentrations of several hundred ppm in 572 many of the Worumba samples, compared to a few tens of ppm in some Neoproterozoic (e.g. 573 Hurtgen et al., 2004) and Mesoproterozoic carbonates (e.g. Kah et al., 2004; Gellatly and 574 Lyons, 2005), suggests that the water column was enriched in dissolved sulfate, probably as 575 a result of evapo-concentration, and thus somewhat buffered against these diagenetic 576 effects. Similar buffering has been described in modern sulfate-rich systems (Rennie and 577 Turchyn, 2014).

\subsection{Environmental interpretations}

Despite extensive metamorphic alteration and modern weathering effects, a few environmental features can be inferred from the geochemical data, combined with sedimentary features.

5.3.1. Sedimentary features indicative of tidal action. Several sedimentary features noted in our field area provide evidence for the type of depositional setting. Most importantly, herringbone cross-beds as observed in the Cooranna Fm and flaser beds documented from the lower Boorloo Siltstone (see also Rowlands et al., 1980; Preiss, 1987) (Figure 4i) may suggest tidal influence during the deposition of these strata. Herringbone cross-stratification can be misidentified if it is only exposed in two dimensions (Awramik and Buchheim, 2009);

591 plane, supports our interpretation of bi-directional current flow, consistent with a tidally-

592 influenced setting. Flaser bedding has been described from a lacustrine setting (Martin, 593 2000), but they are generally considered a hallmark of tidal influence on shallow marine 
594 strata, reflecting frequent waxing and waning of depositional energy (Reineck and 595 Wunderlich, 1968; Longhitano et al., 2012). Mud drapes in Archean and Mesoproterozoic 596 strata have previously been used to infer marine conditions (Flannery et al., 2016; Stüeken 597 et al., 2017a). Hence the wave-rippled sandstones with desiccation cracks and carbonates 598 with gypsum pseudomorphs probably represent the intertidal to supratidal zone. If the basin 599 was connected to the ocean, then the plane-laminated black shales and siltstones likely 600 represent transgressive intervals. It would thus make sense if the Boorloo Siltstone were 601 correlative with either the Kirwan Siltstone or the Worumba Siltstone Mbr, but our data 602 cannot affirm this conclusion.

603 The basin likely also had a fluvial input, as evidenced by unidirectional current 604 indicators (asymmetric ripples) and fluvial channel deposits in the basal Curdimurka 605 Subgroup (Figure 4e, Preiss, 1987) and consistent with the observed trend in CAS isotope values. However, the abundant deposits of sulfate and halite evaporites (Figures 4c, 4f, 3d, $6073 \mathrm{e}, 3 \mathrm{f}, 5 \mathrm{a}, 5 \mathrm{~b}$ ) were probably a result of frequent (daily or monthly) seawater incursions that 608 replenished the salt content of the water column. Subsequent evaporation at low tide would 609 have resulted in salt deposition on exposed surfaces and led to stagnant anoxic conditions in 610 deeper waters. Collectively, our observations thus point to a marginal marine setting, 611 perhaps akin to a sabkha.

613 5.3.2. Redox stratification. The relatively high $\mathrm{Fe}_{\mathrm{HR}} / \mathrm{Fe}_{\mathrm{T}}$ ratios in carbonate-rich samples, 614 where loss of reactive iron may have been minimized due to $\mathrm{pH}$ buffering (Section 5.1.1), 615 may suggest anoxic conditions at the sediment-water interface, at least in this facies. We note 616 that many of these carbonates contain gypsum/anhydrite nodular pseudomorphs with a 617 chicken-wire fabric (Figure 4f, 3d, 5a) and are stromatolitic, which means that sulfate was 618 stable in these environments and that these may have been sites of active $\mathrm{O}_{2}$ production. 619 However, these properties are not incompatible with the iron data. First, sulfate is 620 thermodynamically stable in the presence of $\mathrm{Fe}^{2+}$ (Brookins, 1988), and so ferruginous 621 anoxic conditions do not preclude the formation of gypsum precipitates within sediments 622 under evaporitic conditions as suggested by the chicken-wire fabric. Second, the iron 623 speciation proxy may only capture redox conditions within a few centimeters above the 624 sediment-water interface. For example, it is possible that $\mathrm{Fe}^{2+}$ diffused upwards within 
625 sediments during diagenesis and became trapped and concentrated in shallow-water

626 carbonates. A similar process has been documented from modern settings (Raiswell et al.,

627 2019). Hence surface waters were most like oxygenated.

628 However, deeper waters were probably anoxic as supported by the gradient in the 629 nitrogen isotope data observed in the Boorloo Siltstone, where the black shales show 630 relatively lighter values compared to the overlying carbonates (we exclude the basal strata 631 from this discussion due to potential overprinting by hydrocarbon migration but note that 632 they support the inferred trend). The amphibolite facies metamorphic overprint prohibits 633 accurate reconstructions of primary $\delta^{15} \mathrm{~N}$ values, but if we assume an offset of 3-4\%, then 634 the black shales and carbonates would fall around $0 \%$ and $+6 \%$, respectively. Values near $6350 \%$ are indicative of biological $\mathrm{N}_{2}$ fixation (Zerkle et al., 2008; Zhang et al., 2014), which 636 dominates in environments that are relatively depleted in fixed nitrogen. In contrast, 637 positive values of around $+6 \%$ are typically interpreted as evidence of nitrate assimilation, 638 where the nitrate reservoir was isotopically fractionated by partial nitrate reduction to $\mathrm{N}_{2}$ 639 (denitrification) at an oxic/anoxic interface in the water column (Sigman et al., 2009; Ader 640 et al., 2016; Stüeken et al., 2016). In other words, these data may indicate that there was a 641 redoxcline and that nitrate was relatively more bioavailable in the stromatolitic carbonate 642 facies, which probably represents shallower water. Occurrences of desiccation cracks in 643 siltstones interlayered with the carbonate beds (Figure 4g) indicate that this facies was 644 shallower than the black shales. Hence, the nitrogen data from the Boorloo Siltstone are 645 broadly consistent with a redox stratified environment that was oxic and nitrate-rich in 646 shallow waters but anoxic and nitrate-depleted at depth and offshore. A similar redox 647 stratification in nitrate availability has been described from other Proterozoic basins 648 (Stüeken, 2013; Koehler et al., 2017),

649 In the Kirwan Siltstone and Worumba Shale Member, reconstructed pre650 metamorphic $\delta^{15} \mathrm{~N}$ values are around +2 to $+3 \%$ (Section 5.2.2). These values are lower than 651 in the modern ocean (around $+5 \%$ to $+6 \%$ ), where nitrate is the major nitrogen source 652 (Tesdal et al., 2013). Similar values are found, for example, in some sedimentary intervals 653 and suspended particulates in the modern Black Sea (Fuchsman and Murray, 2008; Fulton 654 et al., 2012) and may indicate mixing between biomass from $\mathrm{N}_{2}$-fixing organisms (near 0\%o) 655 and nitrate-assimilating organisms (>3\%, Kipp et al., 2018). Hence nitrate was probably not 
656 widely available in the water column during deposition of these siltstone beds, which may

657 again be indicative of some level of redox stratification.

659 5.3.3. Geochemical indicators for a marine influence. The Callanna Basin, in particular the 660 Curdimurka Subgroup, has previously been interpreted as an alkaline lake based on findings 661 of pseudomorphs after shortite in several formations in the Willouran Ranges area 662 (Rowlands et al., 1980). Our geochemical data do not support this interpretation and are 663 instead more consistent with a marine influence. First, the $\delta^{34} S$ data of carbonate-associated 664 sulfate in our samples are comparable to the range proposed for seawater sulfate at that time 665 (+16\%o to $+20 \%$, Gorjan et al., 2000, Figure 6; Canfield and Farquhar, 2009). Our data show 666 a gradient from values around $+20 \%$ in the Worumba Anticline to lower values around $667+11 \%$ in the Willouran Range. If these two sedimentary packages were roughly coeval 668 (Preiss, 1987), then this gradient may indicate influx of seawater from the south with a 669 composition around $+18 \%$ o that was perhaps mixing with some sulfate derived from crustal 670 weathering ( $+6 \%$ o today, Fike et al., 2015) towards the north, consistent with the proposed 671 basin geometry (Preiss, 2000).

672 Second, our nitrogen isotope data are inconsistent with alkaline conditions. 673 Sediments from known alkaline lakes typically display high $\delta^{15} \mathrm{~N}$ values, often up to $20 \%$ o 674 due to the formation and volatilization of $\mathrm{NH}_{3}$ gas from $\mathrm{NH}_{4}+$ at $\mathrm{pH}>9$ (Collister and Hayes, 675 1973; Talbot and Johannessen, 1992; Lent et al., 1995; Menzel et al., 2013; Stüeken et al., 676 2019). Our data show no evidence of this process in any of the study sites. We did not analyse 677 samples that contain putative shortite pseudomorphs, but we did sample from roughly the 678 same interval and locations. Further, we note that the features illustrated by Rowlands et al. 679 (1980) are unlikely to be this mineral. Shortite characteristically has wedge-shaped 680 orthorhombic pyramidal crystals, not the elongate 'match-stick' habit with square cross681 sections shown in our Figure 4a and their Figures 2a and 2b. We speculate that these are 682 instead pseudomorphs after sulfate minerals. The highly alkaline conditions as proposed by 683 Rowlands et al. (1980) are incompatible with the precipitation of gypsum, because alkaline 684 waters are characterised by very low dissolved calcium concentrations due to extensive $685 \mathrm{CaCO}_{3}$ precipitation, such that gypsum cannot reach saturation during evaporation (Garrels 686 and Mackenzie, 1967; Stumm and Morgan, 1996). Hence, there is no evidence that this basin 
687 was an alkaline lake. Instead, the combination of sedimentological and geochemical 688 observations are most parsimoniously interpreted as reflecting a shallow marine basin, 689 perhaps sabkha-like, that experienced occasional transgressions, leading to the deposition 690 of plane-laminated black shales. Future trace element studies on the carbonate facies (e.g., 691 Bolhar and van Kranendonk, 2007; Coffey et al., 2013) may be useful for testing this 692 conclusion.

\subsection{Comparison with the contemporaneous Bitter Springs Formation}

The Callanna Group is roughly coeval with the Bitter Springs Formation in Central Australia (810-800 Ma), which is characterized by an extreme negative carbon isotope excursion of about $10 \%$ o that is also seen in correlative marine basins worldwide (Halverson et al., 2005). In the canonical Bitter Springs section, $\delta^{13} C_{c a r b}$ and $\delta^{13} C_{o r g}$ values co-vary with a near-constant isotopic offset over several hundred meters of stratigraphy (Swanson-Hysell et al., 2010). In contrast, our organic carbon isotope data (Figures 2 and 8) fall around the global long-term average $\delta^{13} C_{\text {org }}$ value of $-27 \%$ (Krissansen-Totton et al., 2015). More negative values would be expected if the Curdimurka Supgroup captured the Bitter Springs excursion. In the Boorloo Siltstone, Hill and Walter (2000) reported some $\delta^{13} C_{c a r b}$ values 7.5\% and -7.1\%o from silty carbonates separated stratigraphically by about 300 meters, but these were bracketed by $\delta^{13} \mathrm{C}_{\text {carb }}$ measurements of $0 \%$ to $+1.5 \%$ and are thus best explained by diagenetic or metamorphic alteration. Hence, we see no expression of the Bitter Springs excursion at least in the intervals of the Curdimurka Subgroup investigated in this study, suggesting that they are not directly correlative with the Bitter Springs isotope anomaly. However, more detail geochronological work is needed to substantiate this conclusion. If the Curdimurka Subgroup is coeval to the Bitter Springs Formation, then the absence of a carbon isotope excursion may warrant further investigation.

\section{Conclusion}

The Callanna Group falls into a key interval in Earth history and could potentially 715 provide novel insights into the evolution of life and environmental conditions at this time.

716 The basin formed during continental rifting (Preiss, 2000) and has previously been 717 interpreted as lacustrine and highly alkaline, based on observations of pseudomorphs after 
718 shortite (Rowlands et al., 1980). Until now, little geochemical work had been done on these 719 rocks to test this hypothesis, primarily due to the strong metamorphic overprint and 720 alteration by modern weathering. Indeed, most pyrite appears to have been lost, limiting our 721 ability to use proxies based on redox-sensitive trace elements. However, our analyses 722 suggest that some primary environmental information can be extracted from such altered 723 rocks. First, acid-buffering by carbonates appears to help with the retention of reactive iron 724 despite oxidative weathering, such that Fенг/Fет ratios are retained while $\mathrm{Fe}$ еу $/ \mathrm{Fe}_{\mathrm{rR}}$ ratios 725 drop. Hence signatures of anoxia can be preserved, even though the distinction between 726 euxinic and ferruginous conditions becomes difficult. Second, relative trends in nitrogen 727 isotopes may be preserved when absolute values are shifted by metamorphic overprint. 728 Nitrogen stored in phyllosilicates is perhaps also more resistant to oxidative weathering 729 than organic nitrogen species. Lastly, carbonate-associated sulfate (CAS) is extractable from 730 rocks up to amphibolite facies metamorphic grade.

731 Despite the limitations of alteration, our data are thus overall suggestive of redox 732 stratification and nitrate limitation in this basin. Oxic conditions were probably limited to 733 shallow waters. Furthermore, our data are inconsistent with the interpretation of an alkaline 734 lake, because we found no evidence of ammonia volatilization resulting in very heavy 735 nitrogen isotopes, which characterises such settings. We also note that high alkalinity is 736 incompatible with the precipitation of sulfate evaporites, which are abundantly present as 737 pseudomorphs in carbonate facies in the Curdimurka Subgroup. Instead, sedimentary 738 features indicative of tidal activity and sulfur isotope ratios of carbonate-associated sulfate 739 that are comparable to coeval seawater sulfate indicate that this basin had a marine 740 connection and was frequently flooded by seawater. These rocks therefore provide little 741 information about non-marine habitats on the Neoproterozoic Earth. Lastly, the absence of 742 the characteristic Bitter Springs carbon isotope anomaly may indicate that the units 743 investigated in this study are not directly correlative with the Bitter Springs Formation and 744 can therefore not serve as an age constraint.

\section{Acknowledgements}

747 We thank Thomas Hearon, George and Anne Morphett, Sharon and Allen McInnis, 748 Barry Write and Chris Reed for logistical advice and support. Stephen Hore, Tony Prave and 
Stuart Allison provided geological insights. We thank Steve Bates (UCR) and Andy Schauer

750 (UW) for technical support. Funding was provided by the NASA postdoctoral program (EES)

751 and by the NASA Astrobiology Institute through the Virtual Planetary Laboratory (RB,

752 Cooperative Agreement No. NNA13AA93A) and the Alternative Earths Center (TWL,

753 Cooperative Agreement No. NNA15BB03A). The Earth-Life Transitions Program of the NSF

754 provided additional funds to TWL. Ashleigh Hood and one anonymous reviewer are thanked

755 for constructive comments that improved the manuscript.

\section{References}

758 Ader, M., Thomazo, C., Sansjofre, P., Busigny, V., Papineau, D., Laffont, R., Cartigny, P. and Halverson, G.P., 2016. Interpretation of the nitrogen isotopic composition of Precambrian sedimentary rocks: Assumptions and perspectives. Chemical Geology, 429: 93-110.

Awramik, S.M. and Buchheim, H.P., 2009. A giant, Late Archean lake system: the Mentheena Member (Tumbiana Formation; Fortescue Group), Western Australia. Precambrian Research, 174: 215-240.

Bebout, G.E. and Fogel, M.L., 1992. Nitrogen-isotopic composition of metasedimentary rocks in the Catalina Schist, California: implications for metamorphic devolatilization history. Geochimica et Cosmochimica Acta, 56: 2839-2849.

Bolhar, R. and van Kranendonk, M.J., 2007. A non-marine depositional setting for the northern Fortescue Group, Pilbara Craton, inferred from trace element geochemistry of stromatolitic carbonates. Precambrian Research, 155: 229-250.

Boyd, S.R. and Phillippot, P., 1998. Precambrian ammonium biogeochemistry: a study of the Moine metasediments, Scotland. Chemical Geology, 144: 257-268.

Brookins, D.G., 1988. Eh-pH Diagrams for Geochemistry. Springer-Verlag, New York.

Canfield, D.E. and Farquhar, J., 2009. Animal evolution, bioturbation, and the sulfate concentration of the oceans. Proceedings of the National Academy of Sciences, 106(20): 8123-8127.

Canfield, D.E., Raiswell, R., Westrich, J.T., Reaves, C.M. and Berner, R.A., 1986. The use of chromium reduction in the analysis of reduced inorganic sulfur in sediments and shales. Chemical Geology, 54(1): 149-155.

Clarkson, M.O., Poulton, S.W., Guilbaud, R. and Wood, R.A., 2014. Assessing the utility of Fe/Al and Fe-speciation to record water column redox conditions in carbonate-rich sediments. Chemical Geology, 382: 111-122.

Clayton, J.L. and Swetland, P.J., 1978. Subaerial weathering of sedimentary organic matter. Geochimica et Cosmochimica Acta, 42(3): 305-312.

Coffey, J.M., Flannery, D.T., Walter, M.R. and George, S.C., 2013. Sedimentology, stratigraphy and geochemistry of a stromatolite biofacies in the 2.72 Ga Tumbiana Formation, Fortescue Group, Western Australia. Precambrian Research, 236: 282-296.

Cole, D.B., Reinhard, C.T., Wang, X., Gueguen, B., Halverson, G.P., Gibson, T., Hodgskiss, M.S., McKenzie, N.R., Lyons, T.W. and Planavsky, N.J., 2016. A shale-hosted Cr isotope record of low atmospheric oxygen during the Proterozoic. Geology, 44(7): 555-558. 
Collister, J.W. and Hayes, J.M., 1973. A preliminary study of carbon and nitrogen isotopic biogeochemistry of lacustrine sedimentary rocks from the Green River Formation, Wyoming, Utah, and Colorado. In: M.L. Tuttle (Editor), Geochemical, biogeochemical, and sedimentological studies of the Green River formation, Wyoming, Utah, and Colorado. U.S. Geological Survey, Denver, CO.

Fanning, C.M., Ludwig, K.R., Forbes, B.G. and Preiss, W.V., 1986. Single and multiple grain U$\mathrm{Pb}$ zircon analyses for the early Adelaidean Rook Tuff, Willouran Ranges, South Australia. Geological Society of Australia Abstracts, 15: 71-72.

Fike, D.A., Bradley, A.S. and Rose, C.V., 2015. Rethinking the ancient sulfur cycle. Annual Review of Earth and Planetary Sciences, 43: 593-622.

Flannery, D.T., Allwood, A.C. and van Kranendonk, M.J., 2016. Lacustrine facies dependence of highly ${ }^{13} \mathrm{C}$-depleted organic matter during the global age of methanotrophy. Precambrian Research, 285: 216-241.

Forbes, B.G., Murrell, B. and Preiss, W.V., 1981. Subdivision of Lower Adelaidean, Willouran Ranges. Quarterly Geological Notes of the Geological Survey of South Australia, 79: 716.

Fuchsman, C.A. and Murray, J.K., S.K., 2008. Concentration and natural stable isotope profiles of nitrogen species in the Black Sea. Marine Chemistry, 111: 90-105.

Fulton, J.M., Arthur, M.A. and Freeman, K.H., 2012. Black Sea nitrogen cycling and the preservation of phytoplankton $\delta^{15} \mathrm{~N}$ signals during the Holocene. Global Biogeochemical Cycles, 26(2).

Garrels, R.M. and Mackenzie, F.T., 1967. Origin of the chemical composition of some springs and lakes. In: W. Stumm (Editor), Equilibrium concepts in natural water systems. American Chemical Society, Washington, D.C., pp. 222-242.

Gellatly, A.M. and Lyons, T.W., 2005. Trace sulfate in mid-Proterozoic carbonates and the sulfur isotope record of biospheric evolution. Geochimica et Cosmochimica Acta, 69(15): 38133829.

Gill, B.C., Lyons, T.W. and Frank, T.D., 2008. Behavior of carbonate-associated sulfate during meteoric diagenesis and implications for the sulfur isotope paleoproxy. Geochimica et Cosmochimica Acta, 72(19): 4699-4711.

Godfrey, L.V., Poulton, S.W., Bebout, G.E. and Fralick, P.W., 2013. Stability of the nitrogen cycle during development of sulfidic water in the redox-stratified late Paleoproterozoic ocean. Geology, 41(6): 655-658.

Gorjan, P., Veevers, J.J. and Walter, M.R., 2000. Neoproterozoic sulfur-isotope variation in Australia and global implications. Precambrian Research, 100(1-3): 151-179.

Haendel, D., Muehle, K., Nitzsche, H.-M., Stiehl, G. and Wand, U., 1986. Isotopic variations of the fixed nitrogen in metamorphic rocks. Geochimica et Cosmochimica Acta, 50: 749-758.

Halverson, G.P., Hoffman, P.F., Schrag, D.P., Maloof, A.C. and Rice, A.H.N., 2005. Toward a Neoproterozoic composite carbon-isotope record. GSA Bulletin, 117(9-10): 1181-1207.

Hayes, J.M., Kaplan, I.R. and Wedeking, K.W., 1983. Precambrian organic geochmistry, preservation of the record. In: J.W. Schopf (Editor), Earth's earliest biosphere - its origin and evolution. Princeton University Press, Princeton, NJ, pp. 93-134.

Hill, A.C. and Walter, M.R., 2000. Mid-Neoproterozoic ( 830-750 Ma) isotope stratigraphy of Australia and global correlation. Precambrian Research, 100(1-3): 181-211. 
Hurtgen, M.T., Arthur, M.A. and Prave, A.R., 2004. The sulfur isotope composition of carbonateassociated sulfate in Mesoproterozoic to Neoproterozoic carbonates from Death Valley. Geological Society of America Special Papers: 177-194.

Kah, L.C., Lyons, T.W. and Frank, T.D., 2004. Low marine sulphate and protracted oxygenation of the Proterozoic biosphere. Nature, 431: 834-838.

Kempe, S. and Kazmierczak, J., 2011. Soda lakes. In: J. Reitner and V. Thiel (Editors), Encyclopedia of Geobiology. Springer.

Kipp, M.A., Stüeken, E.E., Yun, M., Bekker, A. and Buick, R., 2018. Pervasive aerobic nitrogen cycling in the surface ocean across the Paleoproterozoic Era. Earth and Planetary Science Letters, 500: 117-126.

Knoll, A.H. and Nowak, M.A., 2017. The timetable of evolution. Science Advances, 3(5): doi: 10.1126/sciadv.1603076.

Koehler, M.C., Stüeken, E.E., Kipp, M.A., Buick, R. and Knoll, A.H., 2017. Spatial and temporal trends in Precambrian nitrogen cycling: a Mesoproterozoic offshore nitrate minimum. Geochimica et Cosmochimica Acta, 198: 315-337.

Krissansen-Totton, J., Buick, R. and Catling, D.C., 2015. A statistical analysis of the carbon isotope record from the Archean to Phanerozoic and implications for the rise of oxygen. American Journal of Science, 315(4): 275-316.

Kump, L.R., Junium, C., Arthur, M.A., Brasier, A., Fallick, A., Melezhik, V., Lepland, A., CČrne, A.E. and Luo, G., 2011. Isotopic evidence for massive oxidation of organic matter following the Great Oxidation Event. Science, 334(6063): 1694-1696.

Lent, R.M., Lyons, W.B., Showers, W.J. and Johannesson, K.H., 1995. Late Holocene paleoclimatic and paleobiologic records from sediments of Devils Lake, North Dakota. Journal of Paleolimnology, 13(3): 193-207.

Leythaeuser, D., 1973. Effects of weathering on organic matter in shales. Geochimica et Cosmochimica Acta, 37(1): 113-120.

Longhitano, S.G., Mellere, D., Steel, R.J. and Ainsworth, R.B., 2012. Tidal depositional systems in the rock record: a review and new insights. Sedimentary Geology, 279: 2-22.

Lyons, T.W. and Severmann, S., 2006. A critical look at iron paleoredox proxies: new insights from modern euxinic marine basins. Geochimica et Cosmochimica Acta, 70(23): 56985722.

Lyons, T.W., Werne, J.P., Hollander, D.J. and Murray, R.W., 2003. Contrasting sulfur geochemistry and $\mathrm{Fe} / \mathrm{Al}$ and $\mathrm{Mo} / \mathrm{Al}$ ratios across the last oxic-to-anoxic transition in the Cariaco Basin, Venezuela. Chemical Geology, 195(1): 131-157.

Marenco, P.J., Corsetti, F.A., Hammond, D.E., Kaufman, A.J. and Bottjer, D.J., 2008. Oxidation of pyrite during extraction of carbonate associated sulfate. Chemical Geology, 247(1-2): 124-132.

Martin, A.J., 2000. Flaser and wavy bedding in ephemeral streams: a modern and an ancient example. Sedimentary Geology, 136(1-2): 1-5.

McWilliams, M.O. and McElhinny, M.W., 1980. Late Precambrian paleomagnetism of Australia: the Adelaide Geosyncline. The Journal of Geology, 88(1): 1-26.

Menzel, P., Gaye, B., Wiesner, M.G., Prasad, S., Stebich, M., Krishna Das, B., Anoop, A., Riedel, N. and Basavaiah, N., 2013. Influence of bottom water anoxia on nitroen isotopic ratios and amino acid contributions of recent sediments from small eutrophic Lonar Lake, central India. Limnology and Oceanography, 58(3): 1061-1074. 
Moores, E.M., 1991. Southwest US - East Antarctica (SWEAT) connection: a hypothesis. Geology, 19(5): 425-428.

Müller, P.J., 1977. CN ratios in Pacific deep-sea sediments: Effect of inorganic ammonium and organic nitrogen compounds sorbed by clays. Geochimica et Cosmochimica Acta, 41(6): 765-776.

Palya, A.P., Buick, I.S. and Bebout, G.E., 2011. Storage and mobility of nitrogen in the continental crust: Evidence from partially melted metasedimentary rocks, Mt. Stafford, Australia. Chemical Geology, 281(3): 211-226.

Petsch, S.T., Berner, R.A. and Eglinton, T.I., 2000. A field study of the chemical weathering of ancient sedimentary organic matter. Organic Geochemistry, 31(5): 475-487.

Petsch, S.T., Edwards, K.J. and Eglinton, T.I., 2005. Microbial transformations of organic matter in black shales and implications for global biogeochemical cycles. Paleogeography, Paleoclimatology, Palaeoecology, 219: 157-170.

Planavsky, N.J., Bekker, A., Hofmann, A., Owens, J.D. and Lyons, T.W., 2012. Sulfur record of rising and falling marine oxygen and sulfate levels during the Lomagundi event. Proceedings of the National Academy of Sciences, 109(45): 18300-18305.

Planavsky, N.J., Reinhard, C.T., Wang, X., Thomson, D., McGoldrick, P., Rainbird, R.H., Johnson, T., Fischer, W.W. and Lyons, T.W., 2014. Low Mid-Proterozoic atmospheric oxygen levels and the delayed rise of animals. Science, 346(6209): 635-638.

Porada, H. and Behr, H.J., 1998. Setting and sedimentary facies of late Proterozoic alkali lake (playa) deposits in the southern Damara Belt of Namibia. Sedimentary Geology, 58(2-4): 171-194.

Poulton, S.W. and Canfield, D.E., 2005. Development of a sequential extraction procedure for iron: implications for iron partitioning in continentally derived particulates. Chemical Geology, 214(3): 209-221.

Poulton, S.W. and Canfield, D.E., 2011. Ferruginous conditions: a dominant feature of the ocean through Earth's history. Elements, 7: 107-112.

Preiss, W., 1987. The Adelaide Geosyncline: Late Proterozoic stratigraphy, sedimentation, palaeontology and tectonics, 53. Department of Mines and Energy, Adelaide, Australia.

Preiss, W.V., 2000. The Adelaide Geosyncline of South Australia and its significance in Neoproterozoic continental reconstruction. Precambrian Research, 100(1-3): 21-63.

Preiss, W.V., Belperio, A.P., Cowley, W.M. and Rankin, L.R., 1993. Neoproterozoic. In: J.F. Drexel, W.V. Preiss and A.J. Parker (Editors), The Geology of South Australia. South Australia Geological Survey, South Australia, pp. 171-203.

Raiswell, R., Hardisty, D.S., Lyons, T.W., Canfield, D.E., Owens, J., Planavsky, N., Poulton, S.W. and Reinhard, C.T., 2019. The iron paleoredox proxies: A guide to the pitfalls, problems and proper practice. American Journal of Science, 318(5): 491-526.

Reineck, H.E. and Wunderlich, F., 1968. Classification and origin of flaser and lenticular bedding. Sedimentology, 11(1-2): 99-104.

Rennie, V.C. and Turchyn, A.V., 2014. The preservation of $\delta \mathrm{S}_{\mathrm{SO}_{4} 34}$ and $\delta \mathrm{O}_{\mathrm{SO} 4} 18$ in carbonateassociated sulfate during marine diagenesis: A 25 Myr test case using marine sediments. Earth and Planetary Science Letters, 395: 12-23.

Rowlands, N.J., Blight, P.G., Jarvis, D.M. and von der Borch, C.C., 1980. Sabkha and playa ennvironments in late Proterozoic grabens, Willouran Ranges, South Australia. Journal of the Geological Society of Australia, 27: 55-68. 
924

925

926

927

928

929

930

931

932

933

934

935

936

937

938

939

940

941

942

943

944

945

946

947

948

949

950

951

952

953

954

955

956

957

958

959

960

961

962

963

964

965

966

967

968

969

Rudnick, R.L. and Gao, S., 2014. Composition of the continental crust. Treatise on Geochemistry, 4: 1-51.

Schidlowski, M., 1987. Application of stable carbon isotopes to early biochemical evolution on Earth. Annual Review of Earth and Planetary Sciences, 15: 47-72.

Schroeder, P.A. and McLain, A.A., 1998. Illite-smectites and the influence of burial diagenesis on the geochemical cycling of nitrogen. Clay Minerals, 33(4): 539-546.

Sigman, D.M., Karsh, K.L. and Casciotti, K.L., 2009. Ocean process tracers: nitrogen isotopes in the ocean, Encyclopedia of ocean science. Elsevier, Amsterdam.

Slotznick, S.P., Eiler, J.M. and Fischer, W.W., 2018. The effects of metamorphism on iron mineralogy and the iron speciation redox proxy. Geochimica et Cosmochimica Acta, 224: 96-115.

Stuieken, E.E., 2013. A test of the nitrogen-limitation hypothesis for retarded eukaryote radiation: nitrogen isotopes across a Mesoproterozoic basinal profile. Geochimica et Cosmochimica Acta, 120: 121-139.

Stüeken, E.E., Bellefroid, E.J., Prave, A., Asael, D., Planavsky, N. and Lyons, T.W., 2017a. Not so non-marine? Revisiting the Torridonian Stoer Group and the Mesoproterozoic biosphere. Geochemical Perspective Letters, 3(2): doi: 10.7185/geochemlet.1725.

Stuieken, E.E., Kipp, M.A., Koehler, M.C. and Buick, R., 2016. The evolution of Earth's biogeochemical nitrogen cycle. Earth Science Reviews, 160: 220-239.

Stüeken, E.E., Martinez, A., Love, G., Olsen, P.E., Bates, S. and Lyons, T.W., 2019. Effects of pH on redox proxies in a Jurassic rift lake: Implications for interpreting environmental records in deep time. Geochimica et Cosmochimica Acta, 252: 240-267.

Stüeken, E.E., Zaloumis, J., Meixnerová, J. and Buick, R., 2017b. Differential metamorphic effects on nitrogen isotopes in kerogen extracts and bulk rocks. Geochimica et Cosmochimica Acta, 217: 80-94.

Stumm, W. and Morgan, J.J., 1996. Aquatic Chemistry. John Wiley \& Sons, Inc.

Swanson-Hysell, N.L., Rose, C.V., Calmet, C.C., Halverson, G.P., Hurtgen, M.T. and Maloof, A.C., 2010. Cryogenian glaciation and the onset of carbon-isotope decoupling. Science,, 328(5978): 608-611.

Talbot, M.R. and Johannessen, T., 1992. A high resolution palaeoclimatic record for the last 27,500 years in tropical west Africa from the carbon and nitroen isotopic composition of lacustrine organic matter. Earth and Planetary Science Letters, 110: 23-37.

Tesdal, J.E., Galbraith, E.D. and Kienast, M., 2013. Nitrogen isotopes in bulk marine sediment: linking seafloor observations with subseafloor records. Biogeosciences, 10(1): 101-118.

Thomazo, C. and Papineau, D., 2013. Biogeochemical cycling of nitrogen on the early Earth. Elements, 9(5): 345-351.

Thomson, D., Rainbird, R.H., Planavsky, N., Lyons, T.W. and Bekker, A., 2015. Chemostratigraphy of the Shaler Supergroup, Victoria Island, NW Canada: A record of ocean composition prior to the Cryogenian glaciations. Precambrian Research, 263: 232245.

van de Kamp, P.C., 2016. Potassium distribution and metasomatism In pelites and schists: how and when, relation to postdepositional events. Journal of Sedimentary Research, 86(6): 683-711.

Von der Borch, C.C., 1980. Evolution of late proterozoic to early paleozoic Adelaide foldbelt, Australia: Comparisons with postpermian rifts and passive margins. Tectonophysics, 70(12): 115-134. 
970 Wotte, T., Shields-Zhou, G.A. and Strauss, H., 2012. Carbonate-associated sulfate: experimental 971 comparisons of common extraction methods and recommendations toward a standard 972 analytical protocol. Chemical Geology, 326: 132-144.

973 Zerkle, A., Junium, C.K., Canfield, D.E. and House, C.H., 2008. Production of ${ }^{15}$ N-depleted 974 biomass during cyanobacterial $\mathrm{N}_{2}$-fixation at high $\mathrm{Fe}$ concentrations. Journal of $975 \quad$ Geophysical Research, 113: doi: 10.1029/2007JG000651.

976 Zhang, X., Sigman, D.M., Morel, F.M. and Kraepiel, A.M., 2014. Nitrogen isotope fractionation by alternative nitrogenases and past ocean anoxia. Proceedings of the National Academy of Sciences, 111(13): 4782-4787.

979 